Aus dem Anatomischen Institut der Universität Bern. Direktor: vormals Prof. Dr. med. H. Bluntschli.

\title{
Der praegravide Genitaltrakt und die Praeimplantation
}

\author{
von
}

\section{Kurt FEREMUTSCH}

Mit einer Tabelle, 21 Abbildungen im Text und Tafeln 2-4.

INHALTSVERZEICHNIS

Seite

Einleitung . . . . . . . . . . . . . . . . . . . . 568

Untersuchungsmaterial . . . . . . . . . . . . . . . 570

Beschreibung der Befunde:

Das Ovarium ................. . . 571

Das Epoophoron .. . . . . . . . . . . . . 574

Die Tube . . . . . . . . . . . . . . . . . . 576

Das Endometrium . . . . . . . . . . . . . . 585

Die Vagina . . . . . . . . . . . . . . . . 596

Diskussion der Befunde:

Die cyklischen Veränderungen der Tubenschleimhaut . . . 600

Das Endometrium ............... . . 605

Epoophoron und Vagina . . . . . . . . . . . . . . 613

Zusammenfassung ............... . . 614

Literaturverzeichnis . . . . . . . . . . . . . . . . . . . . 616

Rev. Suisse de Zool., T. 55, 1948. 


\title{
EINLEITUNG ${ }^{1}$
}

\author{
Motto: Nur wem es gelingt, in \\ einer grossen Mannichfaltigkeit \\ der Phänomene das Urphänomen \\ gewahr zu werden, ist geborgen. \\ Carl Gustav Carus, Physis 1860.
}

Es ist für den Naturforscher immer eine besondere Freude, wenn er in seiner Arbeit von der Fülle vieler Eirzeltatsachen zu dem Wenigen und Typischen eines lebendigen Geschehens gelangen kann; und es wird sein Bestreben sein, einmal zu einer Gesamtschau seiner Ergebnisse zu kommen, sein Bemühen, die vielen kleinen und grossen Funde so zu ordnen, dass aus ihnen das Wesentliche sich auskristallisiert. Hat er dieses Wesentliche eines Naturphänomens erkannt, dann steht ihm des Weg offen, auch das Wesen diese Naturphänomens zu verstehen. Dieses aber steht über den sinnlich erfassbaren Erscheinungen; es ist in einem Bilde gleichsam zu schauen und kann nur verstanden und erlebt werden, wenn wir vom Schauen zum Anschauen weiterschreiten; wenn wir uns nicht nur an die tatsächlichen Befunde halten, sondern in ihnen das Symbolhafte zu erkennen vermögen. Die Deutung selber aber liegt nicht im Bereich des Sinnlich-Wahrnehmbaren. Sie ist gleichsam das Erlebnis selber, das Urbild, das einer lebendigen Naturerscheinung inhaerent ist und nun zur gedanklichen und ideellen Form werden will.

Mit diesen wenigen Voraussetzungen wollen wir an unsere Aufgabe herantreten, die Kennzeichen aufzusuchen, die die praeimplantive Phase am Genitale der Säugetiere charakterisieren. Im Verlaufe unserer Untersuchung hat sich nun herausgestellt, dass wir die praeimplantativen Veränderungen nicht genügend zu fixieren vermögen, wenn wir nicht auch die praegravide Umstellung, die das ganze Genitale erfasst, mit in den Bereich unserer Betrachtung hineinziehen. So lernten wir die praeimplantative von der praegraviden Phase als etwas Verschiedenes kennen und versuchten

1 Das Manuskript der vorliegenden Arbeit wurde am 1. Oktober 1946 der hohen medizinischen Fakultät der Universität Bern als Lösung der von der Fakultät gestellten Preisaufgabe eingereicht. Die Arbeit ist mit dem Fakultätspreis für das Jahr 1946 ausgezeichnet worden. 
für beide das morphologisch Erfassbars zu deuten. Wir bemühten uns auch, das Wesentliche beider Phänomene herauszuarbeiten und befreit von individuell bedingten Unterschieden, die Linie aufzuzeigen, die durch das ganze Geschehen bei Mensch und Tier hindurchläuft.

In der Literatur finden sich sehr wenige Angaben über die praeimplantativen Gewebsdifferenzierungen am Endometrium. Das mag einesteils seinen Grund darin haben, dass man — da sich die Umstellungen in sehr frühen Entwicklungsphasen der Keime und noch vor der Placentation abspielen - ihnen zu wenig Aufmerksamkeit geschenkt hat, da meistenteils andere Fragenkomplexe im Vordergrunde des Interesses standen. Es können mithin unsere Betrachtungen nur der Anfang für weitere Bemühungen sein, die uns über die tatsächlichen Verhältnisse bei zahlreichen anderen Vertretern der Säug€tiere Klarheit zu bringen vermögen. Denn hinter diesem Fragenkreis öffnet sich jener andere, nämlich wieweit der Keim selbst imstande ist, vor seiner Nidation das Endometrium zu beeinflussen. Mehr als Hypothesen aufzustellen wird uns schwerlich zustehen. Und doch würden wir es als zu lebensfremd aufgefasst sehen, wollten wir der Meinung huldigen, der Keim würde gleich einem Fremdkörper sich in die praegravide Schleimhaut einnisten und wäre ausserstande, als ein Lebewesen für sich selbst, auch wieder Möglichkeiten zu entfalten, deren Ausdruck am Endometrium uns schon sehr früh auffallen könnte.

Damit sind wir an dem Punkte angelangt, wo wir uns nach dem Wesen der praegraviden Schleimhautveränderungen zu fragen haben, dessen Sinn wir nicht allein nur in zweckgerichteter Hinsicht deuten dürfen. Und man könnte sich etwa vorstellen, dass die praeimplantativen Veränderungen an der mütterlichen Schleimhaut der Ausdruck sind dafür, dass die Keim-Mutter-Beziehung ein polares Phänomen ist. Es sind zwei Individuen, die mit ihren eigenen Lebenskreisen sich berühren, wobei das eine auf die Anwesenheit des Andern zu reagieren vermag. Das bedeutet aber, dass jene „Potenzen“ des Keimes, von denen man seit jeher zu sprechen gewohnt ist, sich nicht nur in einer Induktion, Regulation und Organisation manifestieren, sondern auch in einer weit tieferen Bedeutung gewahrt bleiben: in der Individualität in des Wortes weitestem Sinne (vergl. Feremutsch und Strauss, 1949). 


\section{DAS UNTERSUCHUNGSMATERIAL}

Die zur Untersuchung herangezogenen Objekte sind Schnittserien von Ericulus setosus, einem madagassischen Borstenigel und von Hemicentetes semispinosus Cuv., ebenfalls einem Vertreter der Insektenfresser Madagaskars. Sie gehören der „Sammlung Bluntschli“ an und wurden mir für meine Untersuchungen von Herrn Prof. Dr. H. Bluntschli in liebenwürdiger Weise zur Verfügung gestellt. ${ }^{1}$

Zur besseren Orientierung seien die untersuchten Serien hier zusammengestellt:

Ericulus-Serien :

$$
\begin{aligned}
& 36,36 \mathrm{a} \\
& 62,62 \mathrm{a} \\
& 63,63 \mathrm{a}, 63 \mathrm{~b} \\
& 70 \\
& 64,64 \mathrm{~b} \\
& 31,31 \mathrm{a}, 31 \mathrm{~b}
\end{aligned}
$$

\begin{tabular}{|c|c|c|}
\hline $15,15 \mathrm{a}$ & Tier Nr. 1414 & Metoestrum \\
\hline & , , 1563 & \\
\hline & ,,$\quad 1543$ & Luteinphase \\
\hline & ", 1557 & \\
\hline
\end{tabular}

Tier Nr. 1847

$$
\begin{aligned}
& \text {, „A.T.15 } \\
& \text {, „A.T.15 Ovulationsphase } \\
& \text {, , } 1646 \\
& \text { „ „A.T.18 Luteinphase I } \\
& \text { „ „, A.T.19 Luteinphase II }
\end{aligned}
$$

Hemicentetes-Serien:

Des weiteren stand mir der Uterus samt Adnexe vom Schaf zur Verfügung. Ferner ein Uterus mit Tube und Ovarium einer 23jähr. Frau.

1 Den Herren Prof. Dr. H. Bluntschli, Dr. med. O. Franz, Assistent am gerichtlich-medizinischen Institut, Dr. med.-vet. W. We в E r, Priv.-Doz. und Prosektor am vet.-anat. Institut Bern sei an dieser Stelle für die Ueberlassung des Untersuchungsmaterials mein herzlicher Dank ausgesprochen.

Die Abbildungen 1, 3, 4 und 39 stellte mir in liebenswürdiger Weise mein Freund, Privatdozent Dr. med. Fritz Strauss zur Verfügung. Ich spreche ihm an dieser Stelle meinen herzlichen Dank aus. 


\section{BESCHREIBUNG DER BEFUNDE}

\section{Das Ovarium.}

Wir beginnen die Schilderung der Befunde, die wir als charakteristisch für die praegravide und praeimplantative Phase am Säugetiergenitale ansehen, mit der Darstellung der Verhälnisse am Eierstock.

Der eigenartige Ablauf der Ovulation bei unserem Objekt (Ericulus setosus) und die Tatsache, dass die Befruchtung der Eier v o r der Ovulation noch innerhalb des Follikels erfolgt (STrauss 1938), bedingen es, dass wir auch die Ovulationsphase in den Kreis unserer Betrachtungen hineinziehen müssen. Die Bildung des Corpus luteum setzt ein mit dem allmählichen Ablauf der Ovulation und der fortschreitenden Umbildung des Follikelapparates, wobei für uns die Frage offenbleiben muss, ob zu der Zeit des sich bildenden Gelbkörpers von diesem eine hormonale Wirkung schon ausgehen kann. Wir unterscheiden daher im Folgenden eine $\mathrm{O} v \mathrm{ula}$ tion sphase (in der schon befruch te te Eier ovuliert werden) von einer L u t e i n p h a s e (Courrier 1925) -- dies als Ausdruck der hormonalen Einflüsse auf das Genitale - und sprechen ferner von einer Luteinphase I entsprechend den sehr jungen gelben Körpern (Tubenpassage der Eier) und von einer Luteinphase II mit etwas älteren Corpora lutea.

Wir werden nur soweit auf die Morphologie des Eierstockes eintreten, als sie eine Grundlage für die Beschreibung der Verhältnisse an Epoophoron, Tube, Uterusschleimhaut und Vagina abgeben kann. Wir verweisen für die Einzelheiten in Bezug auf das Ovulationsgeschehen und die Corpus luteum-Bildung bei Ericulus auf die Arbeiten von Strauss (1938, 1939). Für den zweiten Vertreter der Insektivoren, der uns als Untersuchungsobjekt diente - Hemicentetes semispinosus Cus. — sei auf die Studie von LANDaU (1938) hingewiesen.

\section{Der Eierstock während der Ovulationsphase.}

In einem Übersichtsbild des Ovariums finden wir die Rindenzone von vielen primären und sekundären Follikeln eingenommen. Die Primärfollikel liegen oft sehr dicht unter dem Keimepithel; nicht selten aber sind sie bis tief gegen das Mark hin $\mathrm{zu}$ finden. Neben 
diesen normalen Follikel sind sehr viele atretische vorhanden. Die Rindenzone selbst besteht aus einer, oft mehrere Zellagen umfassenden Schicht von epitheloid veränderten Bindegewebszellen, die ihr ein sehr dicht gefügtes Aussehen verleihen ("Peristroma» Kon 1946). Das Peristroma zeigt vor allem in der Umgebung der ovulierenden Eier, bzw. deren Follikel, eine beginnende Auflockerung seines Zellgefüges.

Das Eierstocksmark erweist sich als ein lockeres Maschenwerk aus faserigem Bindegewebe, dessen Zellen deutlich fibrocytären Charakter haben. Es ist Träger der etwas erweiterten Lymph- und Blutgefässe.

In all den untersuchten Serien der Ovulationsphase finden sich die charakteristischen Bilder der ovulierenden Eizelle (Abb. 1). Und es sei an dieser Stelle nochmals darauf hingewiesen, dass die Ovulation bei Ericulus insofern vom typischen Geschehen bei anderen Säugetieren abweicht, als die Bildung eines Graaf'schen Follikels mit Liquorhöhle $\mathrm{n}$ i c h t erfolgt. Vielmehr wird die Eizelle durch die Quellung des Follikelepithels und durch das seitliche Zurückweichen der Theka nach und nach peripherwärts verschoben. Es ist also die Ovulation kein abrupter Vorgang. Bei Ericulus wird die Eizelle allein ausgestossen und alle Zellen des Follikelmantels bleiben zurück (im Gegensatz zu Hemicentetes, wo wir noch bei Eiern der Tubenpassage Zellen der corona radiata antreffen können).

\section{Das Ovarium der Luteinphase.}

Zum Stadium der Luteinphase I mit Furchungsstadien in der Tube gehören 5 junge Corpora lutea.

In der etwas dichter erscheinenden $\mathrm{R}$ i $\mathrm{n} \mathrm{d}$ e $\mathrm{n} \mathrm{z}$ o $\mathrm{n}$ e begegnen uns viele Primärfollikel und ebenso häufig an Zahl atretische. Die sekundären Follikel sind zahlenmässig vermindert anzutreffen.

Das $\mathrm{M} \mathrm{a} \mathrm{r} \mathrm{k}$ ist wesentlich stärker aufgelockert als in der vorher beschriebenen Phase. Vor allem fallen in ihm die sehr stark erweiterten und hyperämisehen Blutgefässe auf. Die Lymphgefässe treten im Gewebsbild etwas zurück. In der Abb. 3 ist ein Corpus luteum dargestellt. Wir sehen im Zentrum des gelben Körpers dessen Stiel längs getroffen. In diesen strahlen vom Mark her Blutgefässe ein und es findet auf dies Weise die Vascularisation des Corpus luteum statt. Das Peristroma ist an der Oberfläche des Gelbkörpers sehr stark verdünnt. 
Zur Orientierung über die Verhältnisse der Luteinphase II dient die Abb. 4. Wir erkennen an der rechten oberen Seite des Ovars gegenüber der Bursenfalte ein Corpus luteum. Es ragt nicht wesentlich über die Rindenzone vor, die im übrigen von zahlreichen heranreifenden sekundären und tertiären Follikeln eingenommen wird. Daneben sind auch zahlreiche Primärfollikel anzutreffen, die nahezu alle in den peripheren Schichten der Rinde liegen. Das $\mathrm{M}$ a $\mathrm{r} \mathrm{k}$ ist sehr stark aufgelockert und es fallen vor allem die erweiterten Lymph- und Blutgefässe auf. Die Lücken des bindegewebigen Maschenwerkes sind von geronnenen Sekretmassen ausgefüllt.

Von den zahlreichen Corpora lutea ist in Abb. 4 eines zur Darstellung gebracht. Alle fünf Corpora lutea zeigen ungefähr dasselbe Aussehen. Die Hauptmasse wird von dem epithelialen Drüsenkörper eingenommen. An seiner Peripherie ist die Theka stark gewuchert, wodurch der epitheliale Anteil des Corpus luteum von einem breiten Wall von Thekazellen umgeben wird. Daneben finden wir als periphere Begrenzung eine Lage Bindegewebszellen von mehr oder minder fibrocytärem Charakter. Unmittelbar unter dem Gelbkörper sind die Blut-und Lymphgefässe besonders deutlich erweitert. Die grösseren Gefässe treten am Hilus an den gelben Körper heran und ihre Kapillaren verzweigen sich in der Theka externa.

Während der ganzen Phase der Corpus luteum-Bildung finden wir sowohl im epithelialen wie im bindegewebigen Anteil allenthalben Mitosen, die auf eine rege Reparationsleistung seitens der Gewebe hindeuten und die beträchtlichen Umbauvorgänge belegen. In einer jüngsten Arbeit hat es Kon (1946) unternommen sich Klarheit über die Neubildung von Eiern zu verschaffen. Den Untersuchungen lag das reichhaltige Ericulusmaterial zugrunde. Wir wollen aus seinen Ergebnissen festhalten, dass ein $\mathrm{N}$ e u bild ung von Eiern wohl vorkommt, aber als ein Ausnahmephänomen zu betrachten ist. Die Neubildung findet vor allem in den ersten Phasen der Gravidität statt. Wieviel wir von diesen Erscheinungen dem Corpus luteum-Einfluss zuzuschreiben haben, ist wohl schwer abzuwägen. Es scheint mir aber immerhin angebracht, darauf hinzuweisen, dass sowohl das Follikelhormon, wie das des Gelbkörpers auf die Teilungsbereitschaft der Zellen (Courrier 1945) und mithin auf die Plastizität des Gewebes einen 
nicht unerheblichen Einfluss haben. Im Hinblick auf die später zu erörternden Befunde sei angedeutet, dass vor allem während der Ovulationsphase im Uterusoberflächen- und drüsenepithel wie auch im Epithel der Tubenschleimhaut eine rege Teilungsneigung besteht, die auf das Vorhandensein von reifen Follikeln zurückgeführt wird (Wimsatt), von der wir aber für unseren Spezialfall der protrahierten Ovulation glauben, dass sie ihren Grund im entstehenden Corpus luteum habe.

\section{Das Epoophoron}

Bei der Schilderung der Veränderungen am Epoophoron beschränken wir uns auf die Verhältnisse, wie sie uns Ericulus darzubieten vermag, da der Nebeneierstock von Hemicentetes in der Arbeit von LANDAU genauer untersucht worden ist. Während der Ovulationsphase bemerken wir am Epoophoron eine gleichmässige Lockerung des bindegewebigen Stromas, das die Kanälchen mit einem lockeren Faserwerk umhüllt (Abb.5). Die Kanälchen selbst bestehen aus einem ein-, bisweilen zweistufigen hohen prismatischen Epithel, dessen Zellen auf einer zarten Basalmembran aufsitzen. Stellenweise tragen sie Flimmerhaare; andere Zellen entbehren des Cilienbesatzes. An der Basis der Zellen liegen grosse hell erscheinende Vakuolen, denen ein grosser runder, locker gebauter Kern aufsitzt. Über den Zellen wölben sich oft grosse Sekretkuppen in das Kanälchenlumen vor, doch sind sie nicht sehr ausgesprochen in der ersten Zeit der Ovulationsphase. Das Kanälchenlumen erscheint im Übersichtsbild infolge der grossen Epithelhöhe nicht so weit wie es bei demjenigen der Luteinphase der Fall ist. In etwas späteren Stadien der Ovulationsphase setzt die Sekretion sehr deutlich ein und das Lumen der Röhrchen ist dementsprechend mit Sekretmassen ausgefüllt (Abb. 7). Kernteilungsbilder sind $a b$ und zu gefunden worden, sie sind aber nicht ein ausgesprochenes Merkmal für die Charakterisierung der Ovulationsphase.

Als Beleg für die Verhältnisse der $\mathrm{L}$ u t e in $\mathrm{ph}$ a s e dient uns die Abb. 6. Sie zeigt eine Übersichtsaufnahme des Epoophoron der Serie 31 b. Gegenüber dem ersten Bild macht sich eine stärkere Verdichtung des Bindegewebes offenbar. Es erscheint viel kompakter und dichter als in der Ovulationsphase. Da die Epithelhöhe der Kanälchen wesentlich abgenommen hat und die einzelnen 

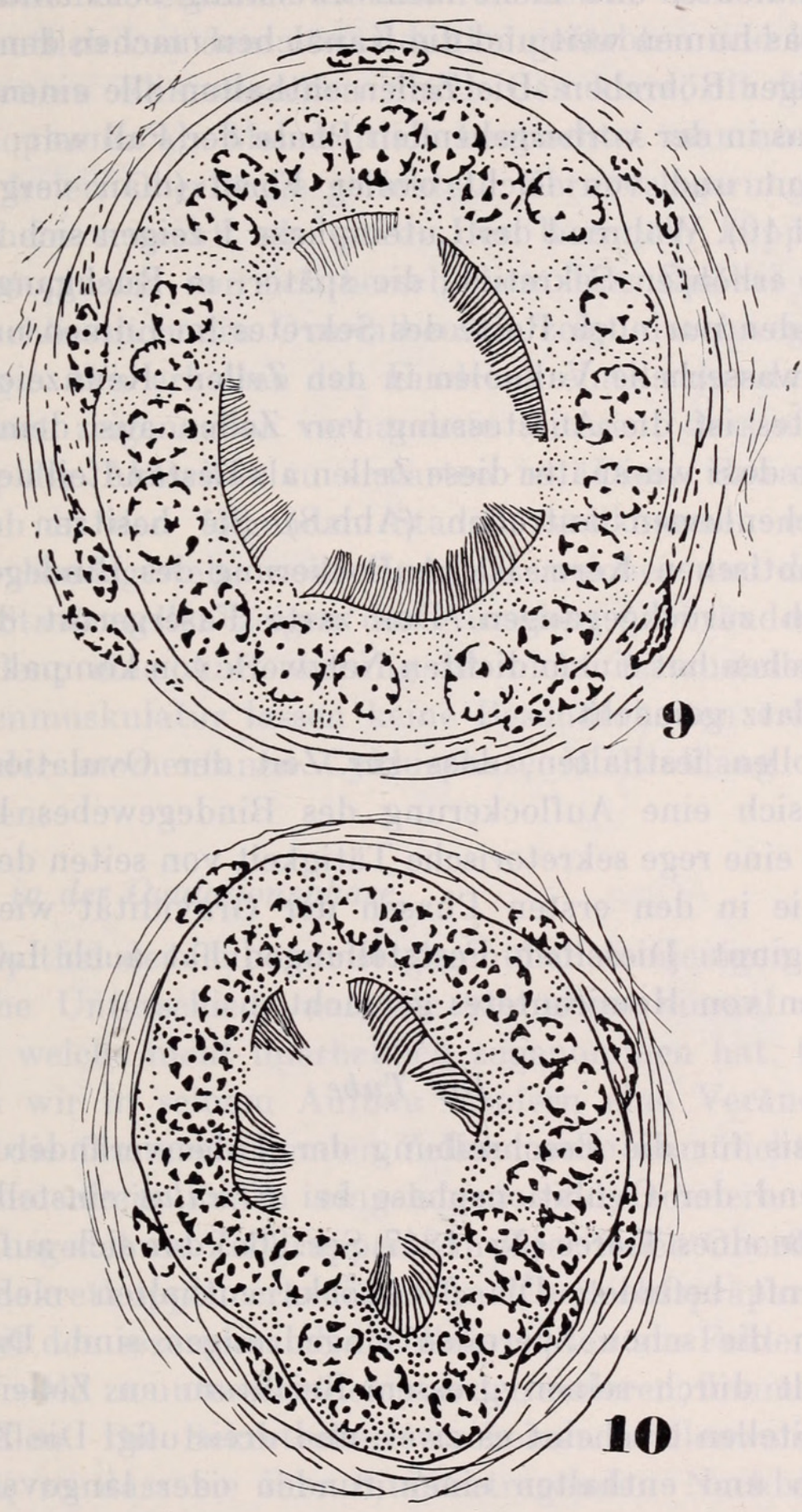

Авв. 9.

Epithel eines Epoophoronkanälchens der Ovulationsphase. Ericulus, Ser. 62. Vergr. ca. 1000-fach.

Авв. 10.

Epithel eines Epoophoronkanälchens der Luteinphase. Stärkere Verdichtung des Bindegewebes, Abnahme der Epithelhöhe, dichtere Lagerung der Zellkerne.

Ericulus, Ser. $31 b$. Vergr. ca. 1000-fach. 
Zellen viel dichter und nicht mehr zweistufig beieinander stehen, erscheint das Lumen weit und die Kanälchen machen den Eindruck dünnwandiger Röhrchen. Die Zellen enthalten alle einen kleineren Kern als das in der vorhergehenden Phase der Fall war; er ist sehr dicht gebaut und von leicht ovaler Form (man vergleiche die Abb. 9 und 10). Während der Luteinphase I zeigen sich alle Merkmale einer erhöhten Sekretion, die späteri m Rückgang begriffen ist. Wir finden nur noch Reste des Sekretes im Lumen und da und dort noch wasserhelle Vakuolen in den Zellen. Kennzeichnend für Hemicentetes ist die Ausstossung von Zellen aus dem Epithelverband, so dass wir später diese Zellen als Bestandteil des Sekretes im Kanälchenlumen antreffen (Abb.8). Sie besitzen alle einen stark pyknotischen Kern. Die Auflockerung des Bindegewebes ist beträchtlich zurückgegangen. Das zarte Fasergerüst der Bindegewebsmaschen hat einem dichten Netzwerk von kompakten Faserbündeln Platz gemacht.

Wir wollen festhalten, dass zur Zeit der Ovulation im Epoophoron sich eine Auflockerung des Bindegewebes bemerkbar macht und eine rege sekretorische Tätigkeit von seiten des Epithels einsetzt, die in den ersten Phasen der Gravidität wieder abzuklingen beginnt. Dieselben Feststellungen hat auch LANDAU am Epoophoron von Hemicentetes gemacht.

\section{Die Tube}

Als Basis für die Beschreibung der Tubenveränderungen, die sich während der Ovulationsphase bei Ericulus einstellen, wähle ich die Tube eines Tieres (Nr. 1847, Ser. 36a) das sich auf der Höhe seiner Brunft befindet. Die Eierstöcke enthalten mehrere reife Follikel, in die schon Spermien eingedrungen sind. Das Tubenepithel fällt durch seinen grossen Reichtum an Zellen auf. An einzelnen Stellen erscheint es zwei- und dreistufig. Die Zellen sind prismatisch und enthalten einen runden oder langovalen Kern, dessen Karyoplasma mässig aufgelockert ist. Ein Vergleich mit den später zu beschreibenden Tubenepithelien zeigt, dass die volle Zell- und Kerngrösse noch nicht erreicht ist. Der Zellverband besteht aus den für alle Säugetiere charakteristischen beiden Formen den flimmertragenden und flimmerfreien Epithelzellen. Das gleichmässig aussehende Flimmerepithel ist aber nicht wesentlich in seinem Gesamtaussehen durch eingestreute flimmerfreie Zellen 
unterbrochen. Wo einzelne flimmerfreie Zellen vorkommen, heben sie sich deutlich von dem etwas dunkel gefärbten und leicht basophil gekörnten Flimmerzellen durch das klare, oft fast wasserhelle Protoplasma ab. Mehrheitlich beobachtet man an ihnen eine nach der freien Oberfläche gerichtete Kernverlagerung, wobei es den Anschein erweckt, als würde der Kern ein kappenförmiges Stück Protoplasma vor sich herschieben. Das Epithel der ganzen Tube einschliesslich des Ovarialbeutels zeigt durchwegs diesselbe Morphologie. Wir erhalten den Eindruck eines ruhenden Epithels, da und dort zeigen aber vorhandene Mitosen, dass eine gewisse Erhöhung der Aktivität zu erwarten ist. Diese Erwartung wird dann auch in den folgenden Stadien vollkommen erfüllt. Das $\mathrm{T} u \mathrm{~b}$ e $\mathrm{n}$ - Bindegewebe weist einen faserreichen und dichten Bau auf. Die Stromazellen zeigen das Aussehen unveränderter Bindegewebszellen; eine Auflockerung ist nicht festzustellen. Gefässe und Tubenmuskulatur lassen keine Besonderheiten erkennen, die wir mit der momentanen Cyklusphase in Einklang zu bringen vermöchten.

\section{Bie Tube in der Ovulationsphase.}

Das Epithel der Tube weist gegenüber demjenigen der Brunft wesentliche Unterschiede auf, die vor allem einmal seine Höhe betreffen, welche nicht unerheblich zugenommen hat. Gleichzeitig bemerken wir in seinem Aufbau insofern eine Veränderung, als zwischen die flimmertragenden Zellelemente nun nicht mehr einzelne flimmerfreie Zellen eingelagert sind, sondern mehr oder weniger ausgedehnte Zellgruppen. An ihrer freien Oberfläche lassen sich oft Sekretkuppen erkennen. Im Übersichtspräparat sind die Stellen mit den sezernierenden Zellelementen am Fehlen der Basalknötchen wohl zu unterscheiden von den anderen, flimmertragenden Epithelzellen. Die Sekretzellen erscheinen stellenweise wie aufgequollen, so dass sie ihre flimmertragenden Nachbarn oft zusammendrücken, wodurch diese zwischen sie eingekeilt werden. Die Kerne der Sekretzellen sind lumenwärts verlagert und bewirken, dass die Kernreihe unregelmässig wird. Nicht selten sind unter den Kernen der Sekretzellen Riesenkerne zu finden (Abb. 12). Das Karyoplasma beider Kernformen (der normal grossen, wie das der Riesenkerne) ist sehr locker und fein strukturiert. Ein weiteres Merkmal, das neben dem gehäuften Auftreten von Sekretzellen 
die Ovulationsphase der Tubenschleimhaut charakterisiert, besteht in der Zunahme der M it o s e n (Abb. 15 und 16). Während wir bei der oben beschriebenen Brunftphase im Übersichtsbild kaum
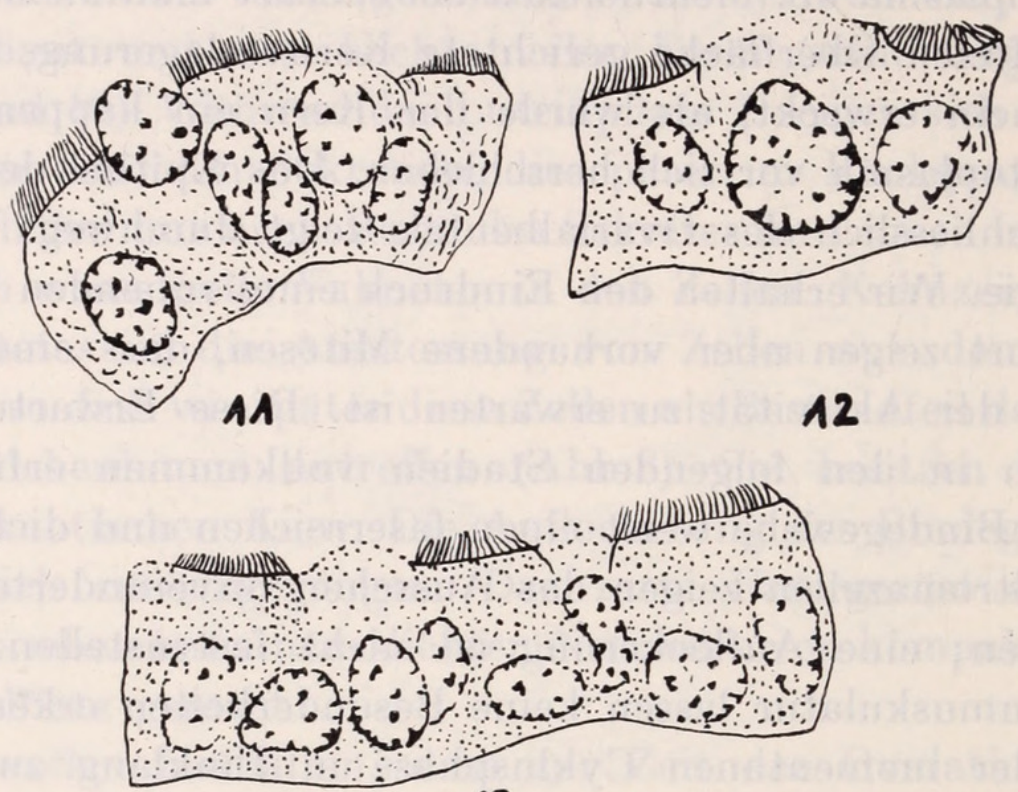

13

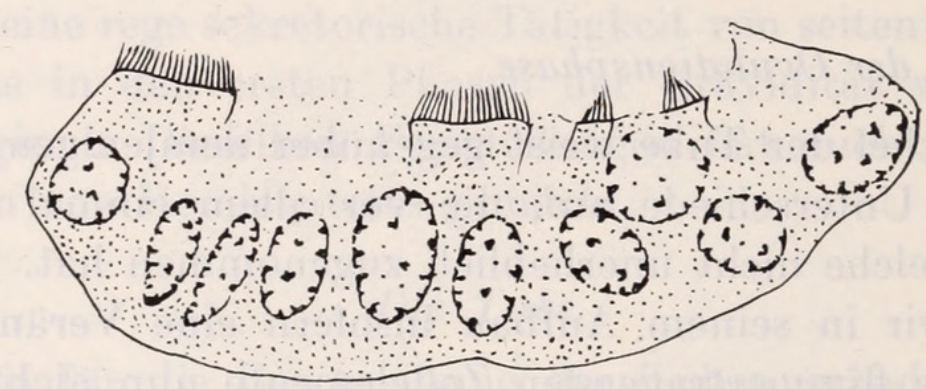

14

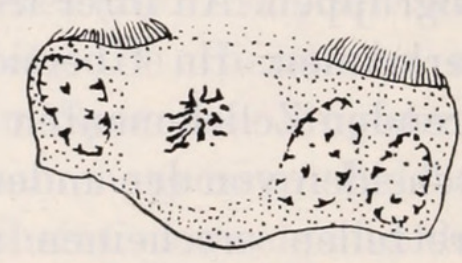

15

Авв. $11-15$.

Ovulationsphase. Epithel der Bursa ovarica.

eine Teilungsfigur zu Gesicht bekamen, zählen wir nun bis zu acht Mitosen in einem Gesichtsfeld. Im Hinblick auf die Literaturangaben möchten wir die Tatsache der vermehrten Mitosen während der Ovulationphase bei Ericulus festhalten. Ausser dem 
Mitosenstoss weisen die $\mathrm{V} \mathrm{a} \mathrm{k} \mathrm{u} \mathrm{o} \mathrm{le} \mathrm{n}$, die vor allem vermehrt in den Sekretzellen anzutreffen sind, auf die erhöhte epitheliale Aktivität des Eileiters hin.

Im $\mathrm{T} u \mathrm{~b}$ en strom a macht sich der Beginn einer Auf-

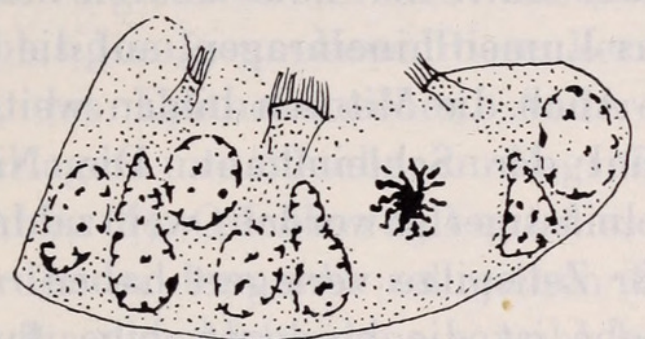

16
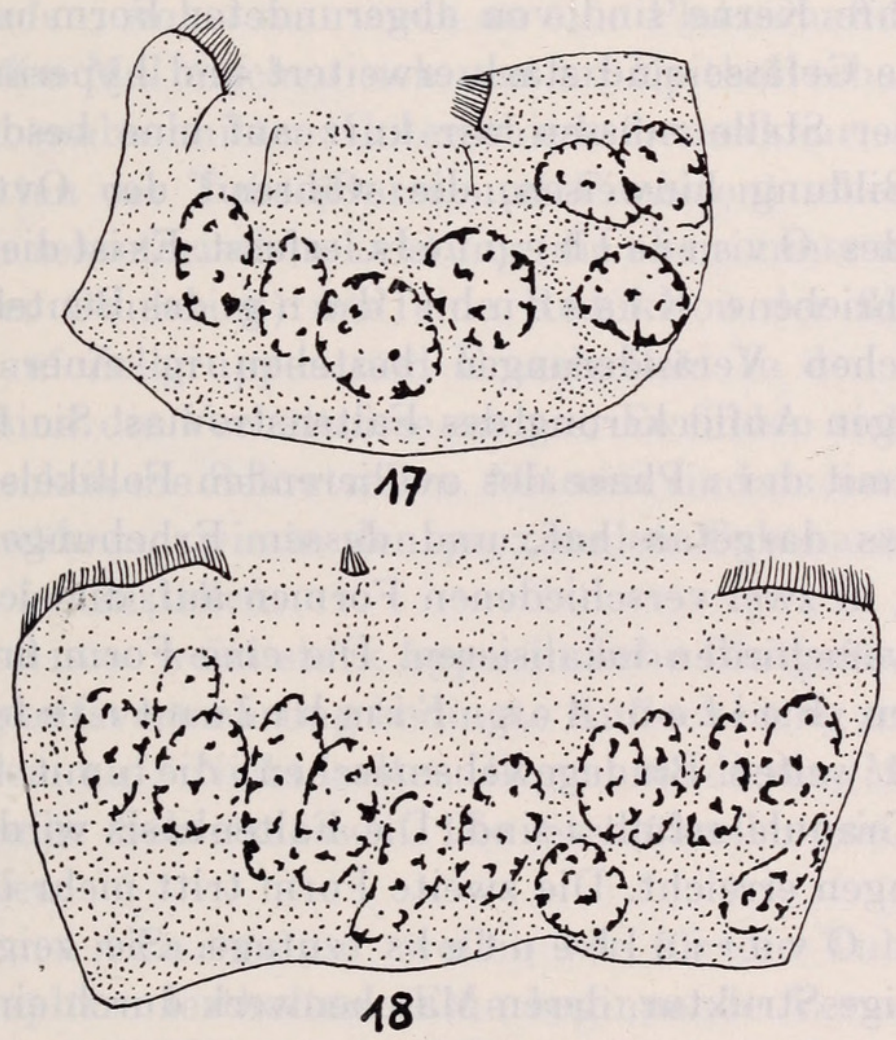

Авв. $16-18$.

Epithel der Ampulla tubae während der Ovulationsphase $(16,17)$.

Epithel der Bursa ovarica während der Luteinphase (18).

lockerung bemerkbar, die Gefässe sind etwas erweitert und sehr gut bis in die Tubenfalten hinein zu verfolgen.

Einen etwas weiter entwickelten Zustand in der epithelialen Umgestaltung der Eileiterschleimhaut stellt die Serie 63 dar. Das Epithel hat weiterhin an Höhe zugenommen und seine Kerne sind, verglichen mit der vorangegangenen Serie, auffallend gross und 
locker gebaut (Abb. 17). Das Cytoplasma ist mit zahlreichen Vakuolen durchsetzt, die sehr oft kappenförmig um den Kern gelagert sind (Abb. 17). Die Sekretzellen bilden auf weite Strecken hin den einzigen Zellbestand und beherrschen vollkommen das Epithelbild. Im Bursaabschnitt der Tube deuten mächtige Sekretkuppen, die weit in das Lumen hineinragen, auf die erhöhte sekretorische Leistung hin. Auch die Mitosen bilden weiterhin ein charakteristisches Merkmal der Schleimhaut. Die Niveaulinie der Kerne ist noch unregelmässiger geworden, weil zahlreiche einzelne Zellkerne sich nach der Zellspitze verlagert haben.

Im Stroma der Tube ist die bindegewebige Auflockerung in vollem Gange. Die einzelnen Zellen selber nehmen daran teil; ihr Leib und ihre Kerne sind von abgerundeter Form und leicht gequollen. Die Gefässe sind stark erweitert und hyperämisch.

An dieser Stelle müssen wir kurz auf eine besondere bindegewebige Bildung hinweisen, die während der Ovulationsphase die Falten des Ovaria $\mathrm{l}$ b e u tels erfasst. Es ist die von Strauss (1946) beschriebene K is s e n bild u n g des Beutelstromas. Die feingeweblichen Veränderungen bestehen in einer ödematösen, grobmaschigen Auflockerung des Faltenstromas. Sie fallen zeitlich zusammen mit der "Phase des ovulierenden Follikels» und treten wie STrauss dargetan hat, und dessen Erhebungen ich bestätigen kann, in zwei verschiedenen Formen auf, die sich auch topographisch verschieden lokalisieren. Die eine Form findet sich vor allem in den Falten des Fimbrientrichters, und besteht aus weiten Bindegewebsmaschen, die "mit feinen, diffus verteilten Granula erfüllt ") sind. Die Faltenbasis wird nie von den Veränderungen erreicht. Die zweite Form tritt mehr in den F a lten des Ovarialbeutels zutage. Sie zeigt eine netzartige, wabige Struktur, deren Maschenwerk durch ein homogenes, leicht azidophil erscheinendes Plasma ausgefüllt ist. Das Epithel weist keine vom typischen Verhalten abweichende Befunde auf. Es ist auf den Kuppen, der vom Oedem erfassten Falten, gedehnt und einschichtig kubisch. In den seitlichen Partien aber wird es einschichtig prismatisch. Die Rückbildung — wie auch die Entstehung - der kissenartigen Bildungen scheint rasch zu erfolgen. Im Stadium der Tubenpassage der Eier ist sie nicht mehr festzustellen. Wir müssen noch kurz im Finzelnen auf die Verhältnisse der Serie 70 eintreten, da es sich in diesem Falle um ein späteres 
Stadium im Ovulationsablauf handelt. Am Bestand der Sekretionszellen hat sich nichts wesentliches geändert. Hingegen finden wir nun häufiger in das Epithel eingelagert schmale, leicht pyknotisch erscheinende Kerne, die man mit den Kernen der Stiftchenzellen (Schaffer) zu vergleichen versucht ist (Abb. 13). Daneben beleben grosse, blasig aufgequollene Riesenkerne, die quergestellt im Zelleib liegen, das Epithelaussehen. Andere Zellkerne sind weit lumenwärts verlagert und offenbar im Begriff, aus dem Zellverband auszutreten (Abb. 11). Offenbar soll auf diese Art und Weise Platz geschaffen werden in dem sehr zellreichen Epithelverband. Kernaustritte sind für den Metoestrus sowohl bei den Tieren (Allen 1922 für die Maus) als auch beim Menschen (Schaffer, Tietze) beschrieben worden, wobei man auch an eine Platzschaffung gedacht hat. Zum ersten Mal machen sich nun im Epithelverhalten in den einzelnen Tubenabschnitten Unterschiede bemerkbar. In den Anfangsanschnitten der Tube (Bursa und Fimbrien) sehen wir einen Rückgang der sekretorischen Leistung (die aber immer noch grösser ist als vor der Ovulation) und eine Reduktion der flimmerfreien Zellstrecken auf Zellgruppen und Einzelzellen. In den ampullären Abschnitten sind die Verhältnisse anders. Es finden sich dort noch auf weite Strecken die Sekretzellen. Mitosen sind da und dort noch anzutreffen, während wir in den proximalen Tubenanteilen Mühe haben solche festzustellen.

Das S t r o m a weist stark hyperämische Blutgefässe und eine durch Flüssigkeitsvermehrung bedingte Auflockerung seiner Bindegewebsmaschen auf. Nicht selten liegen in diesen Maschen geronnene, körnige Sekretmassen. Die Stromazellen sind ebenfalls leicht gequollen.

$\mathrm{Z}$ u s a m m enfassend wollen wir für die Tube während der Ovulationphase festhalten: Eine beginnende Vermehrung der Sekretionsleistung des Epithels; Höhenzunahme des Epithels, Zellvermehrung und Kernausstossung. Im Bindegewebe setzt eine starke oedematöse Auflockerung ein, die in den Ovarialbeutelund Fimbrienfalten zu einer Kissenbildung führt.

Der Eileiter in der Luteinphase.

Unsere Beschreibung umfasst die Serien 64, 64b mit 4-zelligen Furchungsstadien im Tubenisthmus und 31, $31 \mathrm{~b}$ mit 5 implantationsreifen Blastocysten im Uteruscavum. 
Das Epithel der Bursa und der ampullären Tubenabschnitte zeigt eine weitere auffallend starke Höhenzunahme (Abb. 18). Die Kerne liegen basal, besitzen ein sehr lockeres Karyoplasma und sind - verglichen mit jenen der Ovulationsphase - sehr gross, entsprechend der Höhe der Epithelzellen. Im Periovarialraum liegen Kerntrümmer, die mir ein Beweis zu sein scheinen für die tatsächlichen Kernausstossungen, die sich in den vorangehenden Stadien bemerkbar gemacht haben. Die Sekretion scheint nun ohne Zweifel auf ihrem Höhepunkt angelangt zu sein (Abb. 19). Je weiter wir das Epithel gegen den Isthmus hin verfolgen, desto weitere Strecken sehen wir von flimmerfreien Sekretzellen eingenommen und desto mehr gewinnen wir den Eindruck, dass sich die Sekretionsleistung des Epithels uterinwärts verschiebt. Die ausgeprätesten Sekretionserscheinungen sind aber für diese Luteinphase I noch auf die oberen Tubenabschnitte beschränkt. Ebenso hat sich die Teilungsbereitschaft der Zellen uterinwärts verschoben. Es ist die Luteinphase I durch den Höhepunkt der Sekretion charakterisiert.

Eine Stelle des Isthmus verdient nun unsere besondere Aufmerksamkeit, nämlich diejenige, wo das Ei die Tube passiert (Abb. 27). Das Epithel ist dort sehr hoch, oft zwei- und mehrstufig, und es entbehrt streckenweise vollkommen des Flimmerbesatzes. Eine ähnliche Feststellung hat SNy der (1923) am Schweineeileiterepithel während der Eipassage gemacht. Dort, wie auch in unserem Falle, ist das Ei vom Tubenepithel wie von einer dickwandigen Kammer umgeben. Eine besonders starke Tubenerweiterung, wie sie LANDAU bei Hemicentetes beschrieb, trifft für die Verhältnisse bei Ericulus nicht zu. Das stark aufgelockerte T u be n strom a, in dem erweiterte Blutkapillaren $\mathrm{zu}$ sehen sind, ist von zahlreichen Leukocyten durchsetzt. Die Muskulatur bietet keine Besonderheiten dar. Es ist ja selbstverständlich, dass sie, bezw. ihr Bindegewebe an der Auflockerung ebenso teilhat, wie das der Tubenfalten. In einem späteren Zeitpunkt, Luteinphase II (Ser. 31, 31b), zeigen die Tubenepithelien ein wesentliche anderes Aussehen. Es sind Anzeichen vorhanden, die dafür sprechen, dass nun die Sekretionsleistungen des Eileiters langsam abzunehmen im Begriffe sind. Zwischen der Tubenpassage der Furchungsstadien und den dieser Beschreibung zugrunde liegenden Serien mit freien Blastocysten im Cavum uteri ist eine Spanne Zeit verflossen, in 

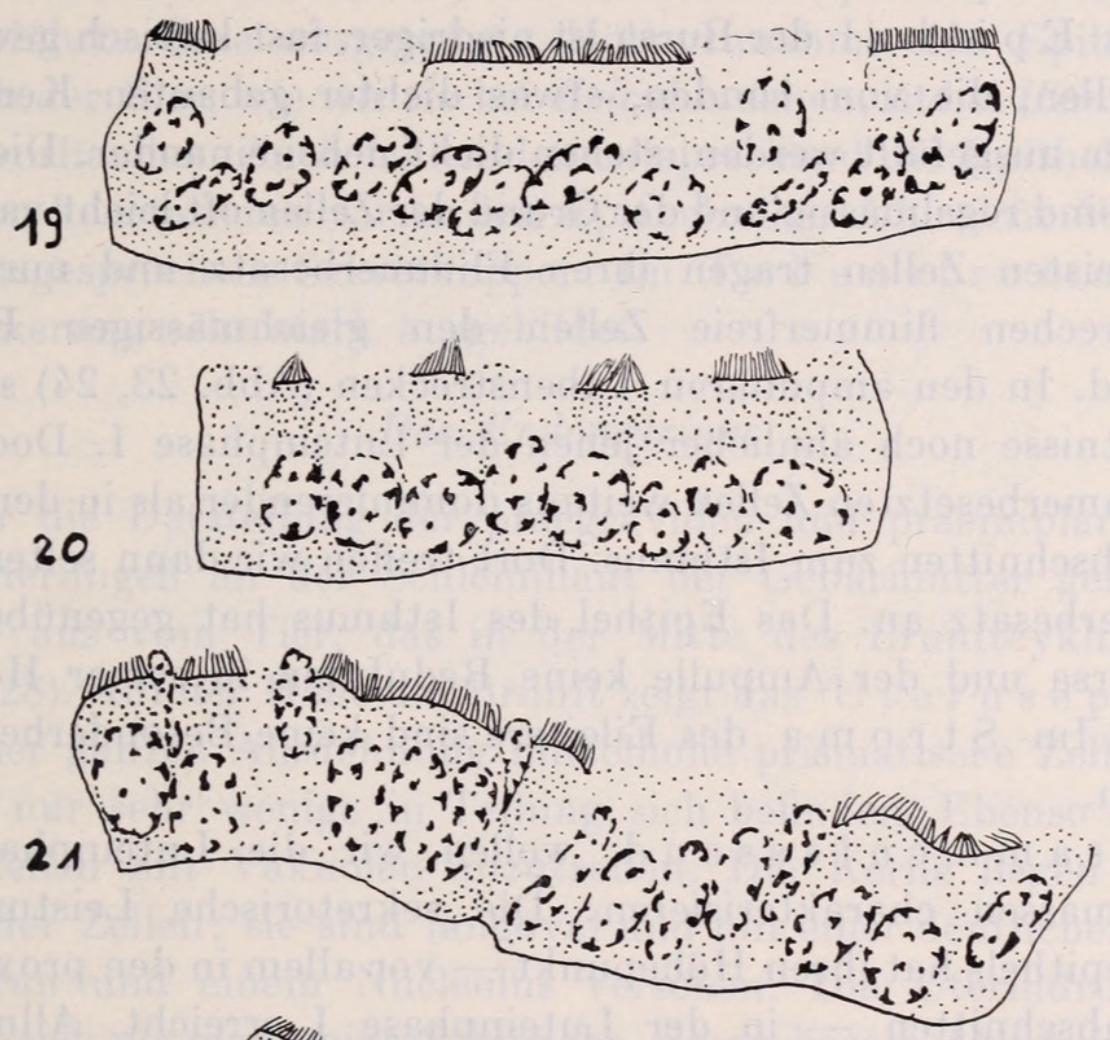

22
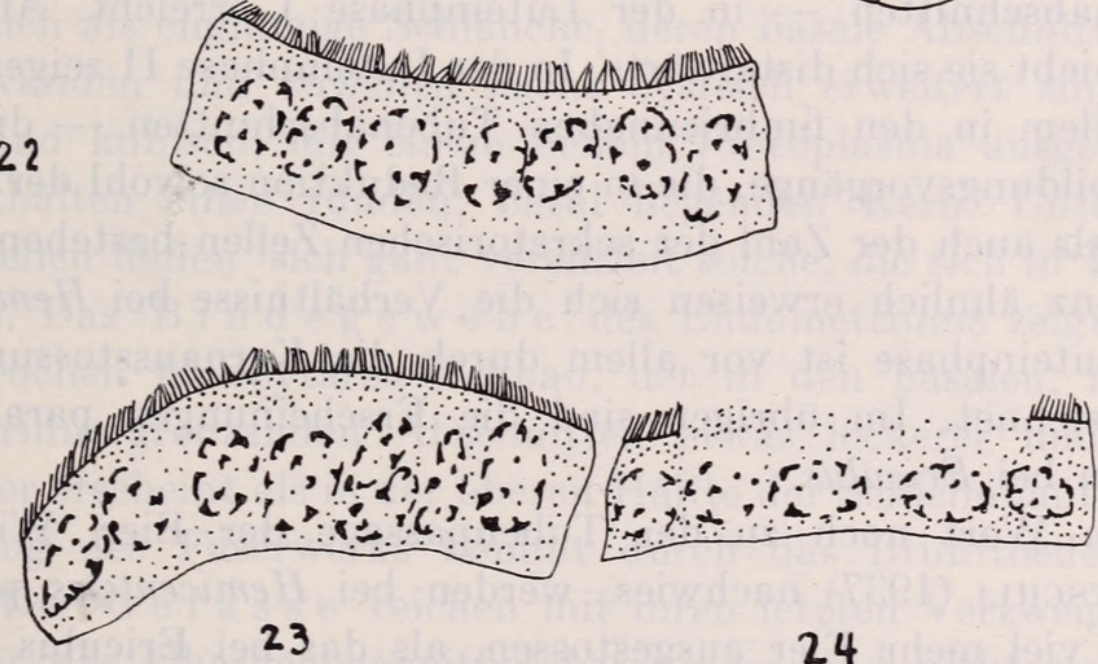

Авв. 19-24.

Tubenepithel der frühen Luteinphase.

19: Ampullenepithel. Ericulus, Ser. 64.

20: Bursa ocarica.

21: Epithel der Ampulle. Hemicentetes, Ser. 43.

Tubenepithel der späten Luteinphase.

22: Epithel der Bursa ovarica. Ericulus, Ser. $31 b$.

23 24: Epithel der Ampulle derselben Serie.

Die Abbildungen 11-24 sind alle in einer Vergrösserung von ca. 1000-fach gezeichnet und geben ein vergleichbares Bild der Epithel- und Kerngrösse In der Originalarbeit waren alle Abbildungen in Aquarell ausgeführt.

Rev. Suisse de Zool., T. 55, 1948. 
welcher sich die Regressionserscheinungen in bezug auf die Sekretion des Eileiterepithels auszubilden vermochten.

Das E p i t h e l der Bursa ist niedriger, fast kubisch geworden. Die Zellen, die vom runden, etwas dichter gebauten Kern vollkommen ausgefüllt werden, stehen dicht nebeneinander. Die Kernreihen sind regelmässig und der Grund der Zellen oft leicht vakuolär. Die meisten Zellen tragen ihren Flimmerbesatz und nur selten unterbrechen flimmerfreie Zellen den gleichmässigen Epithelverband. In den ampullären Tubenstrecken (Abb. 23, 24) sind die Verhältnisse noch ähnlicher jenen der Luteinphase I. Doch sind die flimmerbesetzten Zellen weitaus dominierender als in den Übergangsabschnitten zum Isthmus. Dort treffen wir dann selten einen Flimmerbesatz an. Das Epithel des Isthmus hat gegenüber dem der Bursa und der Ampulle keine Reduktion in seiner Höhe erfahren. Im St ro m a des Eileiters sind keine Besonderheiten zu erheben.

$\mathrm{Z}$ u s a m m e $\mathrm{n}$ fassen d wollen wir die Luteinphase folgendermassen charakterisieren: Die sekretorische Leistung des Tubenepithels hat ihren Höhepunkt -- vor allem in den proximalen Tubenabschnitten - in der Luteinphase I erreicht. Allmählich verschiebt sie sich distalwärts. In der Luteinphase II zeigen sich vor allem in den fimbriennahen Tubenabschnitten - die ersten Rückbildungsvorgänge, die in einer Reduktion sowohl der Epithelhöhe als auch der Zahl der sekretorischen Zellen bestehen.

Ganz ähnlich erweisen sich die Verhältnisse bei Hemicentetes. Die Luteinphase ist vor allem durch die Kernausstossungen gekennzeichnet. Im übrigen sind die Erscheinungen parallel denjenigen bei Ericulus.

Ein Wort noch zu der Tubenpassage der Eier. Wie schon Bunntschli (1937) nachwies, werden bei Hemicentetes pro Ovulation viel mehr Eier ausgestossen, als das bei Ericulus der Fall ist. Dementsprechend finden wir in der Tube oft mehrere Eier in verschiedenen Entwicklungsstadien. Die Eier sind sehr klein nach Bluntschli gehören sie zu den kleinsten Eiern der Placentalier - und oft noch von den Zellen des Follikelepithels umgeben. Die Furchung geschieht innerhalb der Zona pellucida und noch während der Ampullenpassage die Blascocystenbildung, wobei direkt - ohne Morulastadium - aus der Blastula die Blastocyste gebildet wird (Bluntschli). Landar beschrieb für die Durch- 
wanderung der Eier durch die Ampulle eine starke Erweiterung des Tubenvolumens, was er auf den Mittransport von Flüssigkeit zurückführt. Eine ausgeprägte Höhenzunahme des Epithels im Bereich der Eier, wie wir sie bei Ericulus sahen, ist bei Hemicentetes nicht vorhanden. Auch fehlen dementsprechend die Epithelgruben, dagegen konstatieren wir in den Epithelzellen zahlreiche Vakuolen und ausgesprochene Sekretkuppen. Im $\mathrm{T} u \mathrm{~b}$ e $\mathrm{n} \mathrm{s}$ tro m a ist die Auflockerung sehr stark ausgebildet.

\section{Das Endometrium}

Für die Darstellung der praegraviden und praeimplantativen Veränderungen an der Schleimhaut der Gebärmutter gehen wir wieder aus vom Tier, das in der Mitte des Brunftcyklus steht (Abb. 28). Auf der Höhe der Brunft zeigt das U t e r u s e p i t h e l in seiner ganzen Ausdehnung mittelhohe prismatische Zellen, von denen nur sehr wenige in Teilung sich befinden. Ebenso spärlich sind Zellen mit Vakuolen anzutreffen. Die Kerne liegen an der Basis der Zellen; sie sind langoval und mit einer deutlichen Kernmembran und einem Nucleolus versehen. Die Uterindrüsen erweisen sich als englumige Schläuche, deren basale Abschnitte zum Teil gewunden und zuweilen leicht cystisch erweitert sind. Die Zellen sind kubisch, mit einem hellem Protoplasma ausgestattet und enthalten einen runden, basal liegenden Kern. Unter den Drüsenzellen finden sich ganz vereinzelt solche, die sich in Teilung befinden. Das B in d e g e w e b e des Endometriums zeigt einen ausgesprochen fibrocytären Zellbau, der in den basalen, an das Myometrium grenzenden Abschnitten etwas lockerer und weitmaschiger erscheint als in der oberen Hälfte der Schleimhaut. Diese Lockerung des Faserwerks kommt durch das Brunftoedem zustande. Die Ge fä s s e reichen mit ihren letzten Verzweigungen bis unter das Oberflächenepithel heran; sie sind nicht erweitert und zeigen auch sonst keine besonders auffallende Veränderungen.

\section{Das Endometrium während der Ovulation.}

Wenn wir das Endometrium der Ovulationphase untersuchen, gelingt es uns sofort, zwischen ihm und demjenigen der Brunftphase klare Unterschiede herauszuheben. Die ganze Schleimhaut ist gleichmässig aufgelockert und hat an Höhe wesentlich zugenommen (Abb. 29, 30). Die Maschen des Stromas sind weiter 
gestellt, wobei allerdings die Basalzone im mikroskopischen Bilde heller erscheint, als jene gegen das Lumen zu gelegenen Schleimhautbezirke. Gegen den im Übersichtsbild etwas dunkel erscheinenden Muskelmantel hebt sich das Endometrium scharf und deutlich ab. Die Drüsen stehen, vor allem in ihrem Mündungsbereich weit auseinander; basalwärts reichen sie bis zum Mvometrium. Das Uteruslumen ist spaltförmig und enthält Züge von Spermien, die oft bis in den Grund der Drüsen hinein zu verfolgen sind. Das erste deutliche Merkmal des morphologischen Umbaues für die praegravide Phase sind die Veränderungen, die wir am $\mathrm{O} b$ e r flächenepithel zu erkennen vermögen. Schon bei einem ganz kursorischen Überblick fallen uns die zahlreichen Epithelmitosen auf, die das Gesambild des Epithels beherrschen. Sie befinden sich alle, bis auf ganz wenige Ausnahmen, in der Metaphase. Das Epithel besteht aus einem ein-stellenweise zweischichtigen Zellverband. Die ovalen Kerne mit ihrem lockeren Karyoplasma füllen die Zellen fast vollkommen aus. Das Zellplasma erscheint leicht basophil getönt und wird bei einzelnen Zellen von zahlreichen kleinen $\mathrm{V}$ a k u ole $\mathrm{n}$ durchsetzt. An einigen Stellen zeigt das Oberflächenepithel deutliche Anzeichen einer regen Proliferation, so dass der Kontur unregelmässig vorgebuckelt und erhaben erscheint. Zum ersten Mal finden wir unter dem Epithel die Andeutung einer Basalmembran. Die Serie 70 erweist sich in der praegraviden Umformung als weiter fortgeschritten, indem das Epithel der Schleimhaut an Höhe zugenommen hat und seine Zellen sich allenthalben in einer regen Teilungsphase befinden. Wir finden in jedem Schnitt sehr viele und sehr schöne Epithelmitosen. Auch machen sich Anzeichen einer K e r n v e r l a g e r u n g nach der Zellspitze zu bemerkbar. Die Epithelzellen zeigen auch eine deutliche Vermehrung ihrer Vakuolen und zuweilen finden wir ihre freie Oberfläche von einer Sekretkuppe überwölbt. Die Uterindrüsen sind in ihren oberen zwei Dritteln stark gewunden und das Lumen steht offen, ohne jedoch erweitert zu sein. Die unteren basalen Abschnitte sind gestreckt und reichen bis an den Muskelmantel heran. Das Drüsenepithel setzt sich aus grossen, hellen und kubischen Zellen zusammen, deren runde und stark aufgelockerte Kerne an der Zellbasis liegen. Sehr viele metaphasische Teilungsfiguren (Abb. 32) beleben zu dieser Zeit das Bild der Drüsenepithelien. Ein weiteres Anzeichen 
der sicher erhöhten Aktivität sind die vielen Drüsenzellvakuolen (Abb. 31) und das im Drüsenlumen vorhandene Sekret. Das
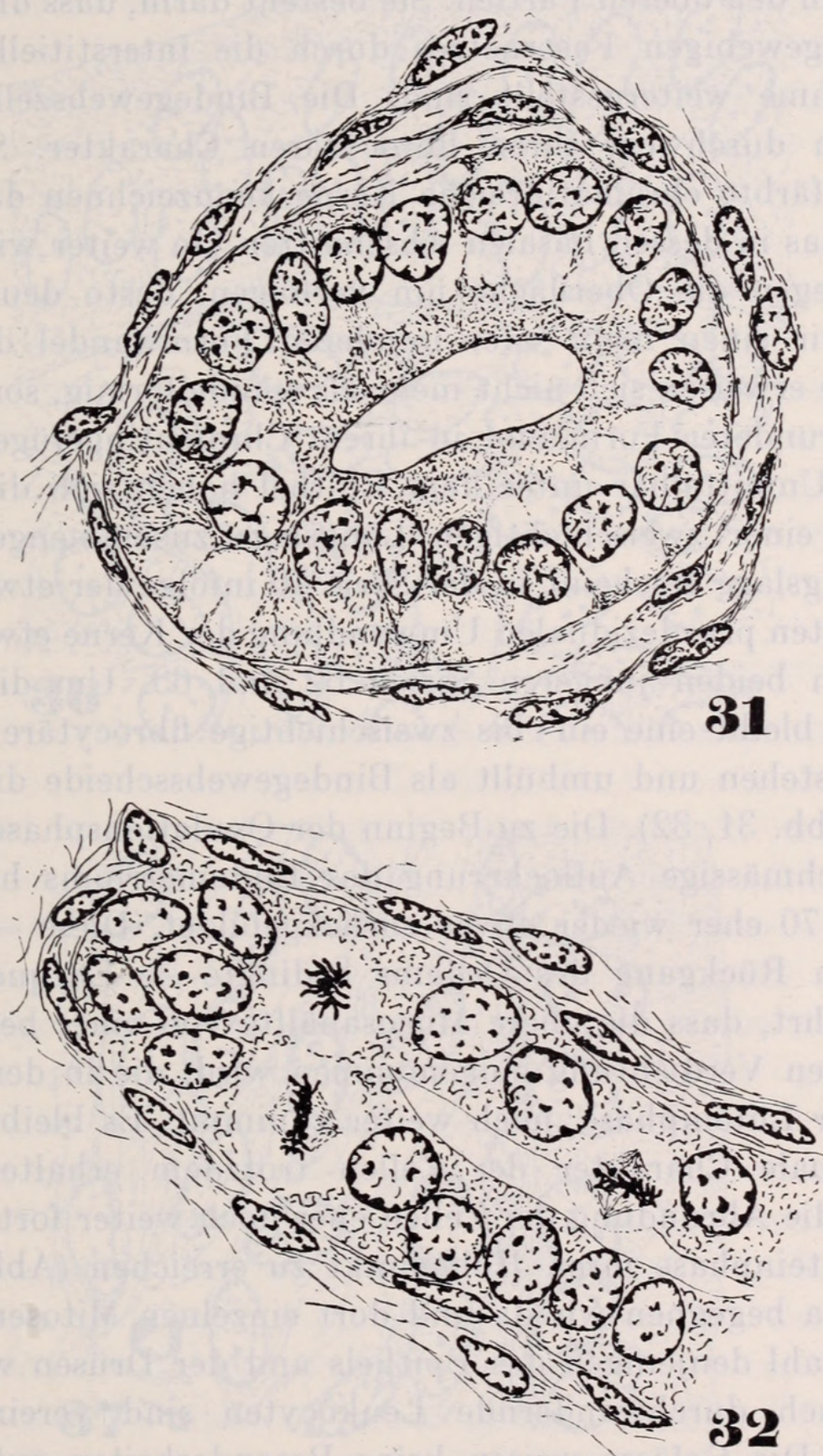

Авв. 31 .

Ovulationsphase. Querschnitt einer Uterindrüse mit starker Vacuolenbildung und fibrocytärer Bindegewebsscheide.

Ericulus, Ser. 62. Vergr. ca. 1000-fach.

Авв. 32 .

Ovulationsphase. Drüsenmitosen.

Ericulus, Ser. 62. Vergr. ca. 1000-fach. 
B i n d e g e w e b e des Schleimhautstromas ist gleichmässig aufgelockert. Die Auflockerung ist in den basalen Zonen etwas deutlicher als in den oberen Partien. Sie besteht darin, dass die Maschen des bindegewebigen Fasernetzes durch die interstitielle Flüssigkeitszunahme weitergestellt sind. Die Bindegewebszellen zeigen aber noch durchwegs ihren fibrocytären Charakter. Spindelige, dunkel gefärbte chromatinreiche Kerne kennzeichnen das Zellbild des Stromas in dessen basalen Abschnitten. Je weiter wir aber das Stroma gegen die Oberfläche hin verfolgen, desto deutlicher erkennen wir einen mehr oder minderen Formwandel der Zellen. Die Kerne erweisen sich nicht mehr als spindelförmig, sondern sind von abgerundeter Form und in ihrem Chromatingefüge sehr viel lockerer. Unmittelbar unter dem Epithel haben sich die Stromazellen zu einer zweischichtigen Längslage zusammengeschlossen. Diese Längslage erscheint in der Serie 70 infolge der etwas stärker ausgeprägten praedezidualen Umwandlung der Kerne etwas dichter als in den beiden jüngeren Serien 62 und 63. Um die Drüsenschläuche bleibt eine ein- bis zweischichtige fibrocytäre Faserlage immer bestehen und umbüllt als Bindegewebsscheide die Drüsenkörper (Abb. 31, 32). Die zu Beginn der Ovulationsphase beschriebene gleichmässige Auflockerung des Endometriums hat sich in der Serie 70 eher wieder etwas zurückgebildet. Diese - offenbar durch den Rückgang des Oedems bedingte -- Entquellung hat dazu geführt, dass die obere Mucosahälfte von einer beginnenden breitzonigen Verdichtung eingenommen wird, die in der nächsten Phase, der Luteinphase, noch weiter zunimmt. Es bleibt aber der praedeziduale Charakter der Zellen trotzdem erhalten und es schreitet die Abrundung der Zellen eher noch weiter fort, um dann in der Luteinphase ihren Höhepunkt zu erreichen (Abb. 36, 37). Im Stroma begegnen wir da und dort einzelnen Mitosen. Sie sind aber an Zahl denjenigen des Epithels und der Drüsen weit unterlegen. Auch durchwandernde Leukocyten sind vereinzelt festzustellen. Die Gefässe weisen keine Besonderheiten auf. Sie sind durch die zunehmende Verdichtung des Stromas oft etwas undeutlich zu erkennen. Im My o me tri u m macht sich ebenfalls eine Auflockerung bemerkbar und in der Serie 70, die ja in allen Teilen eine weiter entwickelte Phase der cyklischen Umwand lungen darstellt, finden wir auch die ersten Zellteilungsbilder. 

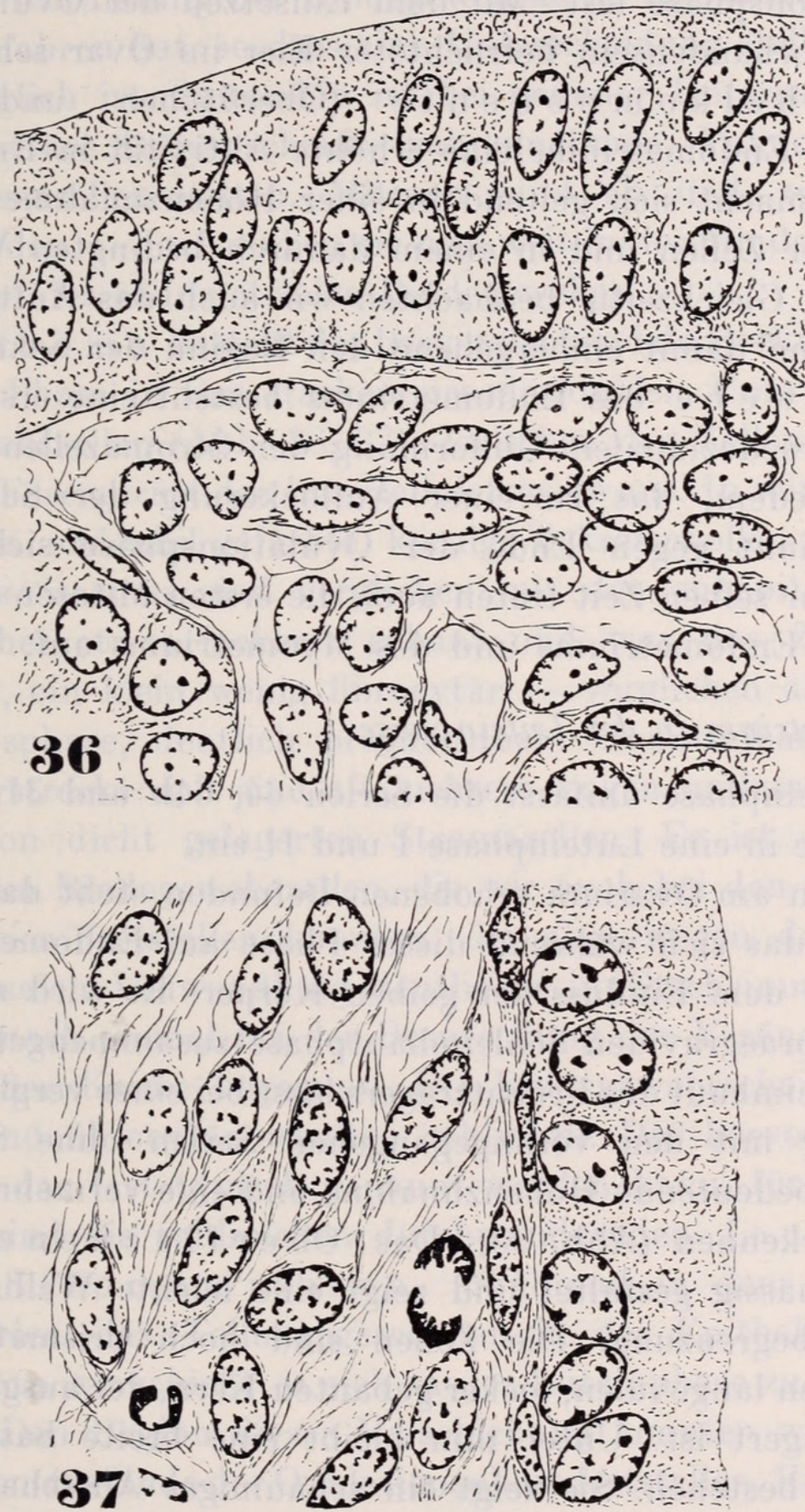

Ав в. 36 .

Ausschnitt des Uterusepithels von Hemicentetes. Luteinphase. Praedeziduale Umwandlung der Stromazellen, fibrocytäre Bindegewebsscheide um die Drüsen. Vergr. ea. 1000-fach.

\section{Авв. 37.}

Ausschnitt aus dem Endometrium im Bereich einer Drüse. Luteinphase. Stromamitose, durchwandernder Leukocyt. Ericulus, Ser. 64. Vergr. ca. 1000-fach. 
$\mathrm{Z}$ u s a m m e $\mathrm{n}$ a s s e $\mathrm{n} d$ halten wir für das Endometrium der Ovulationsphase fest: Mit dem Einsetzen der Ovulation und mit dem Vorhandensein befruchteter Eier im Ovar sehen wir in der Epithelkomponente (Oberflächen- und Drüsenepithel) des Endometriums eine erhöhte Aktivität in Erscheinung treten. Sie macht sich geltend in einer Höhenzunahme und Vermehrung der Zellen und in einem dadurch bedingten Wachstum der Drüsen. Gleichzeitig beobachten wir auch das Auftreten von Vakuolen und damit einhergehend den Beginn der Sekretion. Im B i n d e g e w e b e des Endometriums besteht eine erste Andeutung der praedezidualen Umformung der Stromazellen. Das bestehende Oedem, das zu einer Auflockerung der Schleimhaut führte, beginnt gegen Ende der Ovulationsphase sich zurückzubilden. Zur selben Zeit treten auch die ersten Mitosen im Bindegewebe des Endometriums und des Myometriums auf.

\section{Das Endometrium in der Luteinphase.}

Die Luteinphase umfasst die Serien $64,64 \mathrm{~b}$ und $31,31 \mathrm{~b}$ und wir teilen sie in eine Luteinphase I und II ein.

Nach den am Ovarium erhobenen Befunden steht das gesamte Geschehen, das sich während dieser Phase am Endometrium abspielt, unter dem Einfluss der gelben Körper. Es wird unter dem Begriff der praegraviden Schleimhautphase zusammengefasst.

Die Schleimhaut des Fruchtträgers lässt bei einer vergleichenden Betrachtung mit den vorangegangenen Serien ohne Schwierigkeiten eine bedeutende Höhenzunahme und eine vermehrte Vaskularisation erkennen (Abb. 33). Das Ob e rf lä ch e ne pithel ist unregelmässig gestaltet und zeigt eine leichte Wellung seiner Oberflächenbegrenzung. Die Zellen sind hoch prismatisch und besitzen einen langovalen, locker gebauten Kern, der ausgesprochen apikal verlagert ist. Unter ihm bleibt eine breite basale Cytoplasmazone bestehen. Sie zeigt ein schaumiges Aussehen und ist leicht basophil gefärbt. Das Epithel scheint leicht gequollen zu sein. Eine Basalmembran ist unter dem Epithel vorhanden. Die Ut e rindrüsen erweisen sich als lange, stark gewundene Schläuche, deren Lumen Sekret enthält. Im Mündungs- und Fundusbereich sind die Drüsen nicht selten leicht erweitert. Im Halsbereich stehen die Drüsen sehr eng beieinander, so dass man auf Flachschnitten ihre Kerne kaum von denen des Stromas unter- 
scheiden kann und das vor allem auch deswegen, weil die praedeziduale Abrundung der Bindegewebskerne eine bedeutende Förderung erfahren hat, so dass eine Unterscheidung stellenweise fast nicht möglich ist. Immerhin ist bei genauer Untersuchung noch die fibrocytäre Drüsenscheide wahrzunehmen. Vakuolen sind in den Drüsenzellen selten. Mitosen sind $a b$ und zu noch gesehen worden - doch stehen sie nun weit in der Minderzahl gegenüber denen des endometrialen Bindegewebes.

Im S t r o m a besteht das hervorstechendste Merkmal der praegraviden Phase in der starken praedezidualen Umwandlung der Bindegewebszellen (Abb. 36, 37). Zwischen den Zellen spannt sich das zarte Fasergerüst der Interzellularmasse aus. In seinen Maschen findet man acidophil gefärbte, körnige Sekretschollen. Die basalen Zonen des Stromas sind verglichen mit den subepithelialen Bereichen eher etwas lockerer gebaut und was das Zellverhalten anbelangt, ein klein wenig fibrocytär - verglichen aber mit der Ovulationsphase, deutlich praedezidual! Unmittelbar unter dem Epithel erstreckt sich eine oft mehrere Lagen umfassende Längsschicht von dicht gelagerten Stromazellen. Es ist das dieselbe Schicht von Bindegewebszellen, die wir auch bei den vorangegangenen Serien feststellen konnten, die aber wegen der stärkeren praedezidualen Umwandlung deutlicher in Erscheinung tritt. Sie wird uns noch einmal bei der Besprechung der Veränderungen im Bereiche der Keime begegnen. Die Bindegewebsscheiden um die Drüsen sind fibrocytär erhalten geblieben. Das hervorstechendste Merkmal, das fast typisch genannt werden kann, für die Luteinphase I, sind die zahlreichen durchwandernden Le u k o c y t e $\mathrm{n}$ und die Stromamitosen. Während in den vorangegangenen Serien das Teilungsgeschehen in der Epithelkomponente vorherrschte, verschiebt es sich in der Luteinphase zu gunsten des Stromas. Den Beginn dieser Verschiebung konnten wir allerdings schon gegen das Ende der Ovulationsphase feststellen. Einige Zahlen, die aber keineswegs Anspruch auf Vollständigkeit erheben, mögen das beleuchten.

In der Serie $62 a$ zählten wir in 50 Schnitten 470 Mitosen, davon entfallen auf:

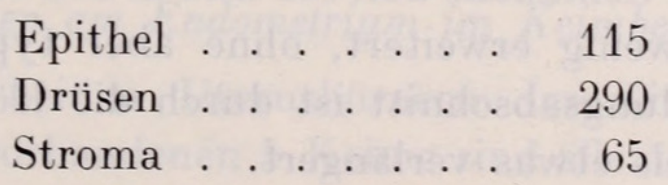


In der S e rie 70 zählten wir in 50 Schnitten 450 Mitosen, davon entfallen auf:

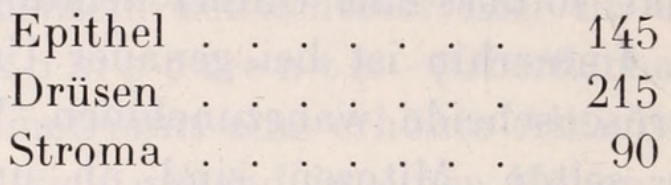

In der Luteinphase der $\mathrm{S}$ e r i e 64 verschiebt sich das Zahlenverhältnis. Wir finden in 50 Schnitten 410 Mitosen, davon entfallen auf:

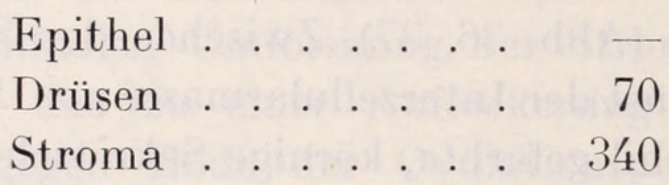

Die G e f ä s s e des Stromas sind allenthalben sehr deutlich ausgebildet, oft leicht sinusartig erweitert.

Das M y o metrium nimmt an der vermehrten- bindegewebigen-Aktivität teil und zeigt neben einer ausgesprochenen Auflockerung zahlreiche Kernteilungsbilder.

Die letzte zu besprechende Ericulus-Serie enthält im Uterus 5 implantationsreife Blastocysten (Serie 31, 31b). Sie entspricht der Luteinphase II. Ich beschreibe vorerst die Veränderungen, wie sie sich am ganzen Endometrium zeigen und trete später auf die lokalen, im Bereich der Keime sich abspielenden Vorgänge ein. Die Höhe des Endometriums (Abb. 34) hat sich im grossen und ganzen unverändert beibehalten.

Das O b e r f l ä che n e p it he l hingegen hat noch einmal eine weitere Zunahme seiner Höhe erfahren. Es weist beträchtliche Falten auf und seine Kerne liegen im Schnittbild infolgedessen oft in mehreren Reihen übereinander. An einigen klar zu überschauenden Stellen findet man die Kerne immer noch apikal gelagert, an anderen Stellen dagegen sind sie in der Mitte der Zellen anzutreffen. Das Epithel steht auf einer gut ausgebildeten Basalmembran, auf seiner freien Oberfläche liegen geronnene Sekretmassen. Die D r üs en weisen eine starke Schlängelung und Verzweigung ihrer Schläuche auf. Sie sind in den Hals- und Fundusabschnitten ein wenig erweitert, ohne aber typische Cysten zu bilden. Der Mündungsabschnitt ist durch die Höhenzunahme des Oberflächenepithels etwas verlängert. 
Die Auflockerung des e n d o metrialen B in dege w e b e s, wie ich sie für die Ovulationsphase beschreiben konnte, und deren beginnende Rückbildung sich in der Luteinphase I bemerkbar gemacht hat, scheint nun endgültig im Schwinden begriffen zu sein. Unter dem Epithel hat sich an der Verdichtungszone des Bindegewebes wenig verändert. In den basalen Teilen der Schleimhaut bleibt die Struktur des Bindegewebes fibrocytär und das Stroma hat einen leicht faserigen Charakter angenommen. Die $\mathrm{G}$ e f ä s s e bleiben weiterhin gewunden und besitzen einen zarten bindegewebigen Mantel. Sie sind aber wenig verschieden von jenen der Luteinphase I, wie ich sie in Abb. 40 dargestellt habe. Auf eine Besonderheit im Gefässverhalten muss an dieser Stelle Bezug genommen werden. STRAuss $(1944 b)$ hat speziell darauf hingewiesen und daraus funktionelle Rückschlüsse gezogen. Wir meinen die stark ausgeprägten sklerotischen Veränderungen im Bereich alter Placentarstellen. Das Stroma ist dort narbig verändert, und von den spiralig verlaufenden, mit breiten hyalinen Scheiden umgebenen Gefässen laufen Narbenzüge bis in das Myometrium. Über den basalen Gefässnarben ist die Mucosa wenig verändert. Wir werden später noch einmal in einem anderen Zusammenhang darauf zurückkommen. Das M y o m e t ri u m ist ohne wesentliche Besonderheiten.

Die bis jetzt beschriebene Morphologie des Endometriums ist charakteristisch für die sogenannte praegravide Phase der Schleimhaut. Sie scheint ohne Ausnahme bei allen Tieren und auch beim Menschen in ihrem typischen Verhalten gleich zu sein und ist als sogenannte Sekretionsphase allgemein bekannt. Die Abb. 35, 38 mögen dafür ein Beleg sein, wie bei allen Tieren mehr oder weniger, das Endometrium eine Auflockerung erfährt und wie offenbar durch das Wachstum die Drüsenschläuche gewunden werden. Abb. 38 zeigt ein Übersichtsbild eines Endometriums während der Luteinphase beim S c h a f. Auch da bemerken wir am Epithel eine beginnende Kernverlagerung nach apikal, eine starke Schlängelung der Drüsenschläuche und die beginnende praedeziduale Umformung des subepithelialem Stromas.

\section{Die Veränderungen am Endometrium im Keimbereich.}

Die in den beiden Uterushörnern des Tieres Nr. A. T. 19 (Serie $31,31 b$ ) vorhandenen 5 Keime sind alle ungefähr gleichweit 
entwickelt; sie sind implantationsreif. Ihre Durchmesser liegen zwischen $70-90 \mu$ (Strauss 1943). Die Zona pellucida ist erhalten. Die Keimblase besteht aus einer Trophoblasthöhle, an deren einen Seite wir den Embryonalknoten erkennen können. Die übrigen Wandstrecken werden von dem einschichtigen Trophoblast eingenommen. Die Bildung des Entoderms hat noch nicht eingesetzt (Abb. 39). Die Keime liegen der Uterusschleimhaut eng an, ohne dass es aber an irgend einer Stelle schon zur Arrosion des Oberflächenepithels gekommen wäre. Und doch bestehen von seiten des Endometriums Veränderungen, die näher zur Betrachtung herangezogen werden sollen. Sie stehen noch im Anfang ihrer Bildung und scheinen geringsfügiger Natur zu sein, erweisen sich aber bei näherer Untersuchung als nicht unerheblich unterschieden von den praegraviden endometrialen Gewebsdifferenzierungen und scheinen ein Beweis dafür zu sein, dass die Schleimhaut durch die Anwesenheit der Keime zu einer Reaktion veranlasst wird. Schon in der Übersichtsaufnahme (Abb. 39) vermögen wir unterhalb des Keimes im Bindegewebe der Schleimhaut eine dreieckförmige, dunkel erscheinende Verdichtungszone wahrzunehmen. (Man vergleiche dazu Abb. 34.)

Das $\mathrm{Oberflächenepithel} \mathrm{ist} \mathrm{im} \mathrm{Bereich} \mathrm{der} \mathrm{Keim-}$ blase proliferiert, so dass eine muldenförmige Einsenkung zustande gekommen ist, die mit ihren freien Rändern den Keim fast bis zum Aequator umfasst. Die Epithelzellen zeigen keine als Degenerationserscheinungen $\mathrm{zu}$ deutende Veränderungen. In die vom Epithel gebildete Bucht münden stets auch Drüsen ein, so dass der Keim nicht mehr frei in der Uterushöhle liegt, sondern gleichsam in einen Becher aufgenommen worden ist, den die Schleimhaut gebildet hat. Auf der den Keimen gegenüberliegenden Schleimhautsêite (wobei wir feststellen wollen, dass wir die eigentliche Implantationsseite nicht mit Sicherheit bezeichnen können!) bemerken wir ausgedehnte Bezirke, in denen die Drüsenschläuche c y s t i s c h erweitert sind (Abb. 42). In den erweiterten Drüsen finden wir Sekretschollen und eine Wucherung der Epithelien. Topographisch fallen die Drüsencysten immer mit einem Schleimhautbezirk zusammen, der zwischen zwei zur Implantation sich anschickenden Keimen liegt. Ausserhalb der offenbar zukünftigen Implantationsfelder sind keine cystischen Erweiterungen mehr zu sehen. Hingegen treffen wir dort auf die Gefässveränderungen 
alter Placentarbezirke. Ausserhalb der Keimbereiche sind die Drüsenschläuche sehr eng und das Lumen ist frei von Sekret. Zwischen den Drüsenerweiterungen erweist sich das Bindegewebe stark verdichtet, was wohl nur zum Teil auf eine mechanische Wirkung zurückgeführt werden kann. Denn eine Stromaverdichtung hat allenthalben im Keimbereich eingesetzt. Vor allem unter dem Epithel hat sich die parallel zum Epithel verlaufende mehrschichtige Zellzone, die nun vier bis fünf Zellagen umfasst, deutlich dezidual verändert. Die Grenze zwischen Epithel und Stroma ist oft sehr unscharf und bisweilen scheint eine Basalmembran zu fehlen. Der Bezirk des stärker verdichteten Stromas umfasst ungefähr einen Drittel der Schleimhaut und reicht eine Strecke weit in der Längsrichtung des Uterushornes über die Keime hinaus.

Für die Gefäs s e der Luteinphase II beschrieben wir im Allgemeinen zarte, bindegewebige Scheiden, die vor allem die Schleimhautkapillaren umhüllen. Im Keimbereich sind diese Hüllen viel ausgeprägter und umgeben als zelluläre Scheide die sehr stark verzweigten Schleimhautgefässe (Abb. 41). Diese Gefässe sind vor allem in jenen Schleimhautbezirken gefunden worden, in denen wir die Drüsencysten angetroffen haben.

Parallel zu den Befunden bei Ericulus führen wir noch diejenigen bei Hemicentetes an. Zur Untersuchung standen uns Serien mit Blastulae im Uterus und der Tube zur Verfügung. Einige der Keime scheinen eben an ihrem Implantationsort angelangt zu sein. Die generellen Veränderungen der Luteinphase sind mit geringfügigen individuellen Abweichungen dieselben und ich kann für beide Objekte die Verhältnisse zusammenfassen. Am O b e r flächenepithel steht die Höhenzunahme der Zellen mit den nach der Zellspitze zu verlagerten Kernen im Vordergrund der morphologischen Differenzierung. Die Niveaulinie der Epitheloberfläche ist durch die bestehende Faltung unregelmässig geworden.

Die D r üs e n zeigen die bekannte Schlängelung und Verzweigung ihrer Schläuche. Bei Hemicentetes scheint die Vakuolenbildung in den Drüsenzellen ausgeprägter zu sein als bei Ericulus. Mitosen waren weder im Oberflächenepithel noch im Epithel der Drüsen vorzufinden.

Das B in d e g e w e b e der Schleimhaut zeigt eine etwas weniger deutlich ausgeprägte praedeziduale Umwandlung seiner 
Zellen. Die oedematöse Durchtränkung ist - im Vergleich mit einem Tier der metoestrischen Cyklusphase - zurückgegangen. Die Dinge liegen also tatsächlich ganz ähnlich wie bei Ericulus. Da der Rückgang des Oedems offenbar unter dem Epithel beginnt, besteht dort eine deutliche stromale Verdichtungszone.

Für den Bereich der Keime haben Buuntschli (1937) und Goetz (1937), die die Frühphasen der Keimentwicklung studiert haben, keine reaktiven Veränderungen beschrieben. In der Tat bereitet es einige Schwierigkeiten, die feinen Unterschiede in der b i n d e g e w e big e n Struktur der übrigen Schleimhaut gegenüber denjenigen des Keimbezirkes abzugrenzen. Doch macht ein genaues Studium eine stärkere Verdichtung und vermehrte praedeziduale Umwandlung der Zellen unmittelbar unter dem Epithel offenbar (Abb. 43). Dort ist es auch zu einer vermehrten Sprossung der Kapillaren gekommen. Am E p it h e l selber entstand durch seine Proliferation eine kleine seichte Einbuchtung, die die Blastula (deren Zona pellucida noch erhalten ist) etwas umgreift. Die D r üsen weisen im Keimbereich ebenfalls cystische Erweiterungen auf. Es scheint die keimbedingte morphologische Umwandlung des Endometriums erst in ihren Anfangsstadien zu stehen, weshalb die Bilder nicht so scharft zu zeichnen sind, wie es bei Ericulus der Fall war oder wie es die südafrikanischen Forscher für ihre Objekte dartun konnten. In einem späteren Stadium der Entwicklung ist der Keim (Blastocyste, Zona pellucida gesprengt!) mit seiner einen Hälfte in die Schleimhaut eingesunken. Im Gebiet der Einsenkung ist das Epithel der Schleimhaut „zu einem Plasmasee aufgelöst". Im umgebenden Bindegewebe zeigt sich eine starke Faser- und Kapillarvermehrung und es hat eine deutliche Deziduazellbildung eingesetzt (BLuntschli 1937). Da zu diesem Zeitpunkt die Implantation begonnen hat, können die geweblichen Veränderungen nicht mehr in den Bereich unserer Betrachtung fallen.

Die Vagina ${ }^{1}$.

Es kann sich in diesem Abschnitt und auch im Rahmen der ganzen Arbeit nicht darum handeln, den vaginalen Cyklus bei den

1 Zur Verfügung standen nur die Scheiden einer Serie (63a) der Ovulationsphase und der Luteinphase II (Ser. 31 a). Anderes Material konnte aus Zeitmangel nicht geschnitten werden. 
verschiedenen Säugetieren und im Vergleich mit dem Menschen zur Sprache zu bringen. Die Untersuchungen über diese Frage

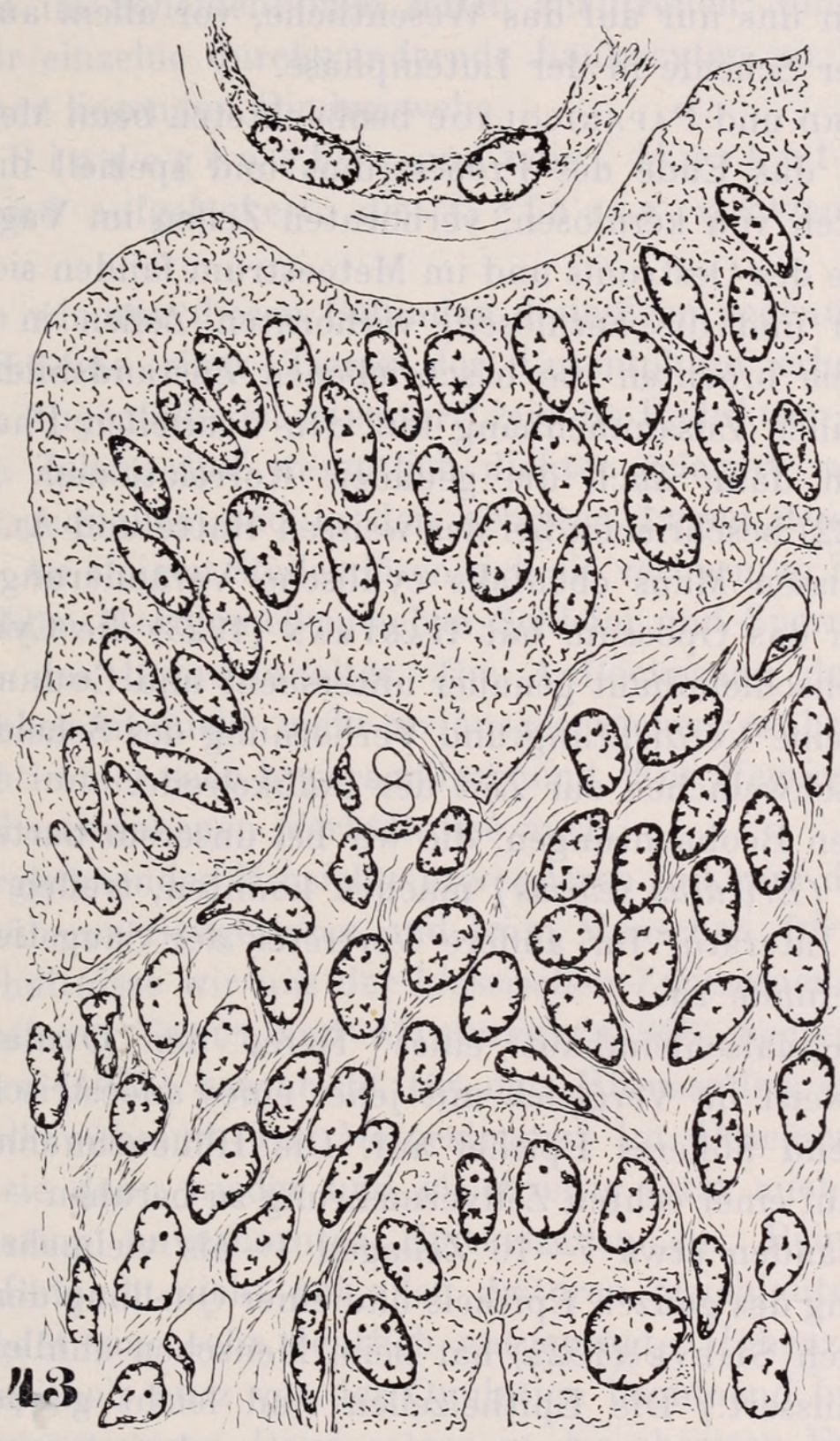

Авв. 43.

Ausschnitt aus dem Keimbereich des Endometriums vom Hemicentetes. Angelagerte Blastula. Leichte Proliferation des Oberflächenepithels, die zur Bildung einer seichten Mulde geführt hat. Unter dem Epithel beginnende Verdichtung des Stromas und vermehrte Kapillarsprossung. (Man vergl. mit Abb. 36.)

Hemicentetes, Ser. 43. Vrgr. ca. 1000-fach.

sind im Jahre 1917 durch die Arbeit von Stockard und PapaNICOLAOU inauguriert worden und das Problem hat im Laufe der 
Zeiten eine grosse Zahl von Studien gefunden. Heute ist das Schrifttum so stark angewachsen, dass es kaum zu übersehen ist. Wir beschränken uns nur auf das Wesentliche, vor allem auf die Morphologie der Scheide in der Luteinphase.

Stockard und Papanicolaou beobachteten beim Meerschweinchen gegen das Ende des Prooestrums und speziell im Oestrum das Auftreten von kernlosen, verhornten Zellen im Vaginalsekret. Gegen Ende des Oestrums und im Metoestrum fanden sie vermehrt Leukocyten und die kernlosen, verhornten Zellen in Auflösung begriffen. Sie brachten die beschriebenen Zustandsbilder des Sekretes in einen Zusammenhang mit den ovariellen Phaenomenen und zeigten dann auch die genauen Korrelationen. Long and Evans (1922) beschrieben bei der weissen Ratte und Allen (1922) bei der weissen Maus ebenfalls cyklische Veränderungen an der Vagina. Für das Opossum hat Hartuan (1923) die Cyklusphasen der Scheidenschleimhaut genauer untersucht und Courrier (1923) beschreibt eine Verdichtung und Verhornung des Scheidenepithels beim Meerschweinchen zur Zeit der Follikelreife.

Nach den Beobachtungen, die wir bei unserem hartstacheligen Borstenigel (Ericulus setosus) machen konnten, treffen auch hier, die in der Literatur für andere Vertreter der Säugetiere niedergelegten Befunde zu.

Die Vaginalschleimhaut eines Tieres der Ovulationsphase (Abb. 46) weist im Vergleich mit jener eines anoestrischen Tieres ein bedeutend höheres Epithel auf. Die Höhenzunahme scheint nun nicht auf einer echten Zellvermehrung zu beruhen -- in beiden Fällen bestanden etwa 7--10 Zellagen - als vielmehr auf einer Auflockerung des ganzen Epithels und einer Quellung der einzelnen Zellen. (Auch Stieve (1925) hat beim Menschen ähnliche Vermutungen geäussert.) Die Epithelzellen sind leicht gequollen, ihre Kerne deutlich grösser als im Anoestrum und sie zeigen ein sehr lockeres Karyoplasma. In den obersten Zellagen hat sich der Zusammenhang der einzelnen Zellen gelockert oder zum Teil ganz gelöst. Einzelne Zellen stehen im Begriff sich vom Epithelverband zu lösen. Ihre Kerne sind aufgequollen und ganz blass gefärbt. Im Vaginallumen beobachten wir entsprechend den Vorgängen am Epithel ganze Fetzen abgestossener Zellen, die noch in einem lockeren Zusammenhang stehen, neben einzelnen blassrot (Azan) gefärbten Zellen, deren Kerne kaum recht zu sehen sind. Wieder 
andere Epithelzellen lassen eine verwaschene, blassblaue Verfärbung erkennen. Freie Bindegewebszellen oder Leukocyten sind $\mathrm{zu}$ dieser Zeit im Scheidenlumen selten anzutreffen; hingegen beobachten wir einzelne durchwandernde Leukocyten im Epithel und im darunter liegenden Bindegewebe.

Das Bindegewebe und die Muskulatur der Scheide sind aufgelockert; die Gefäs se strotzend mit Blut gefüllt.

Stellen wir nun diesen Befunden diejenigen gegenüber, die wir an der Scheide eines Tieres der Luteinphase erhoben haben (Abb. 47). Augenfällig ist in erster Linie die Reduktion der Epithelhöhe. Die Zellen sind wesentlich dichter gelagert, weniger oder gar nicht gequollen und in den obersten Lagen deutlich v e r h o r n t. An einigen Stellen lösen sich die verhornten Zellschichten und es bilden Hornlamellen neben Schleim und Spermien die Bestandteile des Lumeninhaltes. Die Auflockerung des Scheidenbindegewebes ist nicht mehr so ausgesprochen, während die Gefässe noch immer sehr hyperaemisch sind. Für Hemicentetes gelten die eben beschriebenen Verhältnisse auch.

In vergleichender Hinsicht interessieren uns nun die Vorgänge bei den höheren Säugetieren und beim Menschen, für dessen spezielle Verhältnisse wir uns der klassischen Zusammenstellung von Papanicolaou, Traut and Marchetti (1948) bedienen können.

Corner (1923) beschreibt für den Rhesusaffen einen Leukocytenabfall während des Metoestrums. Im Praemenstruum erscheinen sie dann wieder und gleichzeitig setzt auch eine starke Desquamation unverhornter Epithelzellen ein. Beim Menschen sind die Befunde nicht bei allen Autoren gleichlautend. Dierks (1927) findet eine sehr deutlich ausgeprägte Höhenzunahme des Scheidenepithels kurz vor der Ovulation beginnend bis zum Ende des Praemenstruums. Dann setzen in der obersten Epithelschicht degenerative Veränderungen ein, die in einer Chromatolyse und Pyknose der Zellkerne bestehen. Schon vom 7. Tag des Cyklus an macht sich im Vaginalepithel eine Dreischichtung bemerkbar. In der Mitte des Epithels tritt eine, wenige Zellagen umfassende, Verhornungszone auf (Abb. 48). Auf sie folgt lumenwärts eine breite Zone unverhornter, gequollener Zellen, die dann am Ende des Praemenstruums abgestossen wird. Die Verhältnisse sind also analog denen beim Rhesusaffen, wo ja ebenfalls unverhornte Zell-

Rev. Suisse de Zool., T. 55, 1948. 
lagen abgestossen werden. Mose r (1928) versuchte aus dem Vaginalabstrich beim Menschen Rückschlüsse zu ziehen auf die momentane Cyklusphase, kam aber zu einem negativen Resultat und meint, dass der Vaginalabstrich nicht als diagnostisches Mittel Verwendung finden könne.

In einer neuesten Arbeit amerikanischer Autoren (de Allende, Shorr and Hartman 1945) werden die Scheidenabstriche vom Rhesusaffen und von der Frau miteinander verglichen.

Beide zeigen eine weitgehende Úbereinstimmung in ihrem Zellbild. Beim Rhesusaffen tritt eine sogenannte 2. V e r h o r n u n g s phase (,second peak of the cornfied cells") im Praemenstruum auf, die beim Menschen fehlt. Bei beiden aber besteht die erste Verhornungspase zur Zeit der Ovulation.

Es wäre interessant zu wissen, ob nicht auch bei Ericulus die Verhornung zur Zeit der Luteinphase einer zweiten Verhornungsphase entspräche, wobei eine erste zur Zeit der Follikelreife (ähnlich dem Meerschweinchen) zu erwarten wäre. Bemerkenswert ist das Absinken der Zahl der verhornten Zellen zu Beginn der Luteinphase beim Affen. Bei der Frau steigt die Zahl vorerst an, sinkt dann aber ebenfalls sehr rasch ab.

Die amerikanischen Autoren haben sowohl beim Affen wie bei der Frau die Verhältnisse durch Hormoninjektionen geprüft und bestätigt gefunden.

\section{DISKUSSION DER BEFUNDE}

\section{Die cyklischen Veränderungen der Tubenschleimhaut.}

Seit ungefähr der Mitte der 80er Jahre des vergangenen Jahrhunderts wurden die Epithelveränderungen an der Tube im $\mathrm{Zu}$ sammenhang mit der Menstruation verfolgt. LEOPOLD (1877) beschrieb eine starke Hyperämie und Schwellung der Tubenmucosa am ersten Tag der Menstruation und prägte den Begriff der „Tubenmenstruation". Später stützten Landau und Rheinstein (1892) die Ausführungen Leopolds. Mainzer (1899) zweifelte an einer echten Menstruation der Tube und machte darauf aufmerksam, dass unter pathologischen Momenten immer Blut in der Tube 
anzutreffen sei. Auch Czycewicz (1908) lehnt eine Tubenmenstruation ab. Alle erwähnten Autoren gingen von der Meinung aus, eine allfällige Tubenmenstruation müsste mit einer Blutung einher gehen - eine Annahme, die, wie wir nach den Arbeiten schon von Hitschmann und Adler wissen, nicht unbedingt richtig ist. Denn beide Autoren haben in ihrer Arbeit darauf hingewiesen, dass dann, wenn in der Uterusschleimhaut die Blutung einsetzt, die wesentlichen Momente jener Vorgänge schon abgelaufen sind, die zur Menstruation führen und dass das Hauptgewicht nicht auf die Blutung zu legen ist, sondern auf das, was ihr zeitlich in morphologischer und funktioneller Hinsicht vorausgeht. Ähnliche Überlegungen sind nun grundsätzlich auch auf die Tube anzuwenden, doch wollen wir darauf weiter unten zürückkommen.

Holzв асн (1908, cit. n. Schaffner) richtet in seiner vergleichenden Arbeit die Aufmerksamkeit in erster Linie auf das Epithel und versucht dessen morphologische Veränderungen in einen $\mathrm{Zu}$ sammenhang mit der Brunft zu bringen. Eine eingehende Analyse der sonderbaren Epithelverhältnisse gibt Schaffer (1908) für die Tube der Säugetiere und des Menschen. Er war es, der die beiden Zelltypen - Flimmerzellen und flimmerlose Zellen - klar unterschieden hat und sie genetisch miteinander in Verbindung brachte in der Weise, dass die flimmerlosen Zellen Funktionsstadien der Flimmerzellen sind; ihre Leistung ist eine sekretorische.

Unter den zahlreichen Arbeiten, die eine genaue histologische Analyse des Tubenepithels zum Vorwurf haben, seien nur diejenigen von Moreaux (1913), Westman (1916), Walter (1929) und Minalik (1934) erwähnt.

J ÄGERRoos (1912) machte als erster darauf aufmerksam, dass das Wesentliche an den Tubenveränderungen riicht die Blutung sei (diese ist sogar das Abnorme), sondern es seien die ,cyklischen Veränderungen". In der Folge haben viele Untersucher die epithelialen Umgestaltungen an der Tube mit den Cyklusphasen des Ovars und der Uterusschleimhaut zu koordinieren versucht. Die neueren Arbeiten von Jägerroos (1933), Novak und Everett (1928), Snyder (192'-1) und Tietze (1929) lassen uns das Problem in folgender Weise resumieren: Im Anschluss an die Menstruation zeigt das Epithel niedrige Flimmerzellen, die etwas von den flimmerlosen überragt werden. Diese zeigen oft eine keulenförmige Gestalt (Stiftchenzellen Schaffers) und ragen gegen das Lumen vor. Sehr 
bald aber strecken sich die Flimmerzellen und erreichen mit ihrer Basalknötchenreihe die Höhe der flimmerlosen Zellen. Diese erscheinen dann bald in ihrer Zahl vermindert. Das ist mit dem Ende der zweiten Woche erreicht (Abb. 26). Mit Beginn der zweiten Cyklushälfte findet eine Reduktion der Flimmerzellen statt (Abb. 25, 26). Sie nehmen sowohl an Höhe als auch an Zahl ab bzw. wandeln sich durch Verlust ihrer Cilien in Sekretzellen um. Eine echte Kernausstossung soll beim Menschen nicht stattfinden.

In einer jüngsten Arbeit hat Schaff Ner (1940) - in Anlehnung an JoEL - die cyklischen Veränderungen der menschlichen Tube studiert und die Schleimhautveränderungen analog zur Uterusmucosa in eine Proliferationsphase und in eine Sekretionsphase eingeteilt. Recht aufschlussreich sind die Feststellungen Tietzes (1931) bei Fällen von Ovarialtumoren (Granulosazelltumoren), bei denen er in der Tube von Greisinnen ein sehr jugendliches Epithel vorfand, das ungefähr der Cyklusmitte der geschlechtsreifen Frau entspricht.

Über die Beteiligung des $\mathrm{F}$ alten strom as am Cyklus liegen sehr wenige und uncharakteristische Angaben vor. Es zeigt im Praemenstruum eine leichte Hyperämie und eine geringe Auflockerung der perivaskulären Scheiden, ferner Leukocytenauswanderung während der Menses (Iwata 1929). Joel (1940) sah Gefässprossungen im Faltenstroma am 13.-16. Tag. Imata berichtet über sklerotische Veränderungen besonders der Venen, die er als eine Menstruationssklerose auffasst.

Auch die $\mathrm{Tubenmusklat}$ ur zeigt einen periodischen Wechsel, indem eine Längenzunahme der Fasern während der ersten Cyklushälfte erfolgt, die dann in der Corpus luteum-Phase wieder zurückgeht (ANAPOLsk y 1927).

Bei der offenbar sekretorischen Tätigkeit des Tubenepithels interessierte vor allem die Frage nach dem Charakter des Sekretes. Über das Verhalten des G ly k o ge n s (Tröscher 1917, Imata 1927, Joel 1939 a) und der L i p o i d e (Scheyer 1926, Butomo 1927, Joel 1939 b) in den verschiedenen Cyklusphasen gehen die Feststellungen auseinander und lassen sich nicht zu einem allgemein gültigen Bilde abrunden. Lipoide sind nach JoEL in allen Cyklusphasen in wechselnder Menge und Verteilung vorhanden, während Butomo die Hauptmenge zur Zeit der Menses auftreten sieht. Ähnlich sind die Beobachtungen Scheyers. Eine eingehende 
Bearbeitung hat die Glykogenfrage durch die erwähnten Autoren erfahren. Sie finden die Hauptmenge des Glykogens in den ersten Stadien der Sekretionsphase hauptsächlich in den Flimmerzellen. Gegen Ende der Sekretionsphase nimmt der Gehalt an Glykogen ab. Zu Beginn der Proliferationsphase ist kein Glykogen in den Zellen nachzuweisen. Die Autoren bringen die Abnahme des Glykogens am Ende der Sekretionsphase mit der Ausscheidung ins Lumen in Zusammenhang und sehen in dieser Sekretion eine Ernährungsaufgabe für das Ei während dessen Passage durch die Tube.

Dieses zu den cyklischen Veränderungen an der menschlichen Tubenschleimhaut.

Für die Verhältnisse bei den Säugetieren sind unter den älteren Arbeiten diejenigen von Moreaux (1913) über die Kaninchentube und diejenige von Allen (1922) über die Tube der Maus zu erwähnen. Der Mäuseeileiter zeigt während des Prooestrums und Oestrums eine regelmässige Lagerung der Kerne, die mit dem Einsetzen der metoestrischen Phase langsam gestört wird, dadurch, dass Kernaustritte erfolgen, wobei die Zelle ihre Wimpern verliert, und eine starke Vakuolenbildung in den Zellen einsetzt. Fine genauere Beschreibung des Tubencyklus beim Hund geben Courrier und Gerlinger (1922). Sie versuchen ihre Befunde in einen genauen Einklang zu bringen mit den jeweiligen morphologischen und furktionellen Zuständen am Eierstock. Eine ähnlich eingehende Analyse gibt SNydER (1923) für den Schweineeileiter. Über die Glykogenverhältnisse in der Tubenschleimhaut der Fledermaus unterrichtet uns eine Arbeit von Nakano (1928). Danach tritt Glykogen erst auf, nachdem eine Begattung stattgefunden hat und ist dann bis zur Geburt nachzuweisen. Bei Hemicentetes hat LANDAU (1938) eine verstärkte Sekretion während der Implantation und in frühen Phasen der Gravidität gesehen.

Schon die alten Autoren (Schaffer, Holzbach und andere) dachten bei den zellulären Umwandlungen an eine Sekretionsleistung und Westman (1916) brachte die häufigen Zellteilungsbilder der flimmerlosen Zellen gerade in einen direkten Zusammenhang mit ihrer sekretorischen Leistung, indem er meinte, dass die erhöhte Anforderung an die Zelle eine schnellere Regeneration erfordere. Erst die genaue Korrelation der epithalialen Umwandlungsbilder mit dem jeweiligen ovariellen Funktionszuständen legte den Gedanken nahe, dass das Tubenepithel die Funktion einer 
Drüse versehen könne und Courrier (1945) spricht dann auch folgerichtig von einer ,fonction glandulaire de la trompe". Dieser Drüsenfunktion ist dann noch die der Eileiter gegenüber zu stellen. Nur der Vollständigkeit halber sei darauf hingewiesen, dass der alte Streit des c i l i a r e n (Grosser 1915, 1918) und des m u sk u lär e n (Sовотта 1914, 1916) Eitransportes nicht entschieden ist. Fischel (1914) macht mit Sobotta geltend, dass das cilierte Epithel nicht wesentlich zum Eitransport beitragen könnte, da zu mindest bei seinem Objekt (Mus decum.) dieses eine beschränkte Ausdehnung habe (Isthmus ist ohne Flimmerbesatz!).

Ein Wort noch zur „Tubenmenstruation“. Dass eine Menstruation der Tube im Sinne einer Schleimhautabstossung nicht existiert, darf wohl als ausgemacht gelten. Wenn wir aber die cyklischen Umwandlungen im Auge behalten, dann ist daran die Tube ebenso beteiligt wie der übrige Genitaltrakt. Und wir können JoEL nicht zustimmen, wenn er die „Tubenmenstruation" (wobei dieser Begriff unrichtig ist) als einen unbiologischen Vorgang ansehen will. Denn das, was bei der Uterusmucosa zur Menstruation führt, nämlich die cyklischen Vorgänge, die unter dem Einfluss der Hormone stehen, sind auch am Tubenepithel vorhanden; und es wäre eigentlich ein Unbeteiligtsein an diesen cyklischen Vorgängen ausserhalb eines normalen Geschehens, wenn wir bedenken, dass die Tube ebenso wie Uterus und Vagina den ehemaligen Müller'schen Schlauch darstellen. Wieviel von dieser Annahme als zu Recht bestehend angenommen werden kann, liesse sich wohl nur durch vergleichende Betrachtungen abklären. Wenn wir uns aber andererseits wieder vor Augen halten, dass in der Sekretionsphase in der Tube so gut wie im Uterus dieselben morphologischen und funktionellen Momente in Erscheinung treten, nämlich die Umwandlung des Epithels zu sezernierendem Epithel und die Sekretionsleistung der Uterindrüsen, ferner in beiden das Auftreten von Lipoiden und Glykogen zur Zeit der Luteinphase, dann können wir die Parallelität beider Erscheinungen nicht ohne weiteres von der Hand weisen. Ziel der Leistungen wäre in dem einen Fall Ernährung des Eies auf seiner Wanderschaft, im anderen Fall Ernährung des Eies solange es sich nicht selbst ernähren kann, d. h. noch nicht implantiert ist. Die Quelle zu seiner Ernährung befände sich dann in den in der praegraviden Schleimhaut aufgestapelten Nährstoffen. 


\section{Das Endometrium.}

Die verhältnismässig rasch auf die Ovulation erfolgende Umstellung im morphologischen Verhalten der Uteruschleimhaut darf nun ohne Bedenken den Einflüssen, die vom jungen gelben Körper ausgehen, zugeschrieben werden. Sie besteht ganz allgemein in einer Höhenzunahme des gesamten Endometriums, die vor allem durch die oedematöse Durchtränkung des Bindegewebes bedingt ist und ferner in einem verstärkten Wachstum der Drüsen, deren Epithelien auch zu dieser Zeit zu sezernieren beginnen. Bald macht sich allerdings ein Rückgang des Oedems bemerkbar, der zu einer leichten Verdichtung der Struktur führt und parallel mit ihm geht eine vermehrte praedeziduale Umwandlung der Stromazellen einher. (Van der Horst and Gillman, Wimsatt, Hartman, Schreder). Die eben geschilderten Merkmale der Luteinphase sind bei allen Säugetieren mehr oder minder genau die gleichen. Man vergleiche etwa die Abbildung der Uterusschleimhaut von Ericulus mit derjenigen vom Schaf und vom Rhesusaffen. Die Parallelen der geweblichen Differenzierungen lassen sich bis in die kleinsten Einzelheiten nachweisen und zeigen, dass dem morphologisch erfassbaren Zustandsbild funktionell ein typisches Geschehen zugrunde liegt. In diesem Zusammenhang möchten wir auf das Auftreten der Epithelmitosen in Oberflächen- und Drüsenepithelien hinweisen. Sie treten beim Ericulus und Hemicentetes vorzüglich während der Ovulationsphase auf, sind aber mit dem Beginn der Luteinphase vollkommen verschwunden, während an ihrer Stelle das Teilungsgeschehen in den Bindegewebszellen des Stromas und der Muskulatur tritt. Dieselben Beobachtungen machte Wimsatт $(1944 b)$ bei der Fledermaus Myotis und van DER Horst and Gillman $(1942 a)$ beschreiben ähnliches für Elephantulus. Bei anderen Vertretern der Säugetiere liegen die Verhältnisse analog, so beim Hund (Keller 1909), beim Opossum (Hartman 1923) und bei der Maus (Allen 1922). Die ausgesprochene Zellvermehrung in der Epithelkomponente der Schleimhaut ist schliesslich nur die nötige Voraussetzung für die während der Luteinphase festgestellte Wachstumszunahme. Wiмsatт $(1944 a)$ hat sie in $\mathrm{Zu}$ sammenhang mit der Bildung der GraAF'schen Follikel gebracht, d. h. das Follikelhormon für die Vermehrungsphase in der Epithelkomponente der Schleimhaut verantwortlich gemacht. (Man ver- 
gleiche dazu das von uns beim Ovar Gesagte.) Dass mit dem Beginn der Luteinphase die Mitosen aus dem Bild der Epithelien verschwinden, lässt sich doch wohl nur so verstehen, dass die nun einsetzende Sekretion - also die spezifische Arbeit der Zelle einen Teilungsvorgang nicht mehr zulässt, während auf der anderen Seite die Stromazelle sich teilen kann, wodurch gleichzeitig nicht nur (durch die Vermehrung der Zellen) ein Wachstum und eine Auflockerung erfolgt, sondern das Gewebe auch gleichsam jugendlicher erhalten wird, was für seine zukünftige Aufgabe von nicht unerheblicher Bedeutung zu sein scheint.

Die Umgestaltungsvorgänge, die wir eben darzustellen uns bemühten, und ihr morphologischer Ausdruck, decken sich bei den verschiedenen Säugetieren weitgehend und können in Parallele gesetzt werden zu der ,praemenstruellen“ Schleimhaut des Menschen, wie sie uns in klassischer Weise von Hitschmann und Adler (1908) und von Schroeder $(1914,1915)$ beschrieben worden ist und deren Befunde in einer neuesten Arbeit von Hertig and Rоск (1945) ihre Bestätigung gefunden haben. Diese Umgestaltungsvorgänge erfassen das gesamte Endometrium in gleicher Weise und sind in ihrem Ablauf nur abhängig von dem Vorhandensein eines gelben Körpers. Sie stellen Anpassungsvorgänge der Schleimhaut für die Eiaufnahme dar und sind der mütterliche Beitrag zu einer Implantation (Strauss $1944 a$ ). Wir wollen weiter unten noch eingehender auf die feingeweblichen Einzelheiten, die uns diese praegravide Phase charakterisieren, eintreten. Vorerst soll ein anderes Problem näher zur Sprache kommen.

Schon im Verlaufe der Befundbeschreibung haben wir die Keimbezirke der Schleimhaut als etwas Besonderes von dem übrigen Endometrium unterschieden. Das hatte seine Gründe darin, dass wir Reaktionen von seiten der Schleimhaut beobachten konnten, die dem übrigen Endometrium nicht zukamen, und in denen wir eine Antwort auf die Anwesenheit der Keime erblicken. Wir werden in der Folge diese reaktiven Erscheinungen, wie sie sich an Stroma, Gefässen, Drüsen und Oberflächenepithel von Ericulus und Hemicentetes abspielen, näher ins Auge fassen und mit den in der Literatur niedergelegten Angaben vergleichen. Es liegt in der Natur der Sache, dass wir Wiederholungen nicht vermeiden können, wenn wir nicht immer in umständlicher Art und Weise auf die Befundbeschreibungen hinweisen wollen. 
Am bindegewe bigen Strom a des Endometriums beobachteten wir eine ausgesprochene subepitheliale Verdichtungszone. Sie besteht aus einer Lage von mehreren Zellen, die deutlich dezidual umgewandelt erscheinen. Diese Verdichtungszone ist infolge der etwas weiter fortgeschrittenen Dezidualisierung der Zellen unter dem Oberflächenepithel besser charakterisiert, sie ist aber auch nach der Tiefe der Schleimhaut zu recht deutlich nachzuweisen und erfasst etwa einen Drittel der Schleimhauthöhe und geht sowohl cranial als auch caudal noch ein Stück weit über den Blastocystenbereich hinaus. Wir konnten sie auch bei Hemicentetes, allerdings in einer weniger prägnanten Form, nachweisen.

Eine entsprechende subepitheliale Verdichtungszone des Stromas findet sich auch bei Elephantulus (van der Horst and GillMAN $1942 a$ ). Vorgängig dieser Verdichtung, die nach und nach auch das übrige Endometrium (im Keimbereich) mehr oder minder erfasst, beschrieben die beiden Autoren ein Oedem, das sich subepithelial auszubilden beginnt und von eben dorther sich wieder zurückbildet. Es umfasst nur den mesometralen Schleimhautabschnitt, den Bezirk also, der für Elephantulus die zukünftige Implantationsstelle darstellt. Die südafrikanischen Autoren betrachten dieses Oedem als einen Vorläufer des späteren Schwangerschaftsoedems.

Bei Myotis (Wıматт) bestehen die Stromaveränderungen im Keimbereich in einem faserigen Bezirk (,fibrous triangle“), der sich scharf vom übrigen Endometrium abhebt. Er umfasst nur einen kleinen Teil des späteren Implantationsareales und die Zellen sind noch leicht fibrocytär, während jene ausserhalb des faserigen Dreiecks, aber noch innerhalb des Keimbereiches, die typische Form der Deziduazellen besitzen. Auch das praeimplantative Schleimhautoedem konnte bei Myotis nachgewiesen werden.

Am G e fäs s a p a r a t sind die Umgestaltungen nicht minder deutlich zu erheben. Wir beschrieben eine zelluläre Bindegewebsscheide um die Kapillaren des Endometriums, die erst von dem Moment an zu sehen ist, wo der Keim der Schleimhaut anliegt. Mehr oder minder deutlich ist sie auch ausserhalb des Keimbereiches um die Gefässkapillaren zu sehen, doch erreicht sie ihre schönste Ausbildung im Keimbereich selbst.

Für Elephantulus haben van Der Horst and Gillman (1946) in den Frühphasen der Gravidität ähnliche Gefässveränderungen 
gesehen. Sie erfassen dort nicht nur die Gefässe der Schleimhaut, sondern ebenso jene des Myometriums und die grossen Gefässe des Mesometriums. Sie bestehen in einer zellulären Hülle von Bindegewebe, deren Elemente den typischen Deziduazellen gleichen. Als bedeutungsvoll ist festzuhalten, dass sie erst in dem Moment auftreten, wo der Keim das Blastocystenstadium erreicht hat, aber noch nicht in die Schleimhautoberfläche eingedrungen ist. Vielleicht dürfen wir hier nicht gerade von einer ausgesprochen lokalen und keimbedingten Umgestaltung reden, es verdient aber die Feststellung eine grosse Beachtung, dass bei Ericulus die Gefässe im Keimbereich die best differenzierte Gefässhülle tragen.

Über das Verhalten der Ut e r in d r ü s e n konnten wir bei Ericulus und Hemicentetes im unmittelbaren Keimbereich ausser geringen Erweiterungen im Mündungsbereich wenig charakteristisches berichten. Dagegen fanden wir ausgedehnte cystische Erweiterungen der Drüsenschläuche und eine vermehrte Schlängelung derselben jeweils in den Schleimhautabschnitten, die zwischen zwei sich zur Implantation anschickenden Keimen liegen. Der Höhepunkt der Cystenausbildung liegt gerade zwischen zwei alten Placentarstellen, fällt also topographisch mit der Mitte jener Schleimhautfelder zusammen, die Strauss $(1944 b)$ als besonders geeignet für eine neue Keimeinnistung ansehen will. In diesem Bezirk treffen wir auch die oben erwähnten Gefässveränderungen an. Ausserhalb dieses Areales befinden sich die Narben alter Placentarstellen. Dort sind die kleinen und grossen Gefässe sehr stark hyalin verändert. Ihre hyaline Scheide darf aber nicht mit jener zellulären Bindegewebshülle um die Gefässe des Keimbezirkes verwechselt werden. Strauss u. a. haben aus diesem Gefässverhalten an der alten Placentarstelle und aus der jeweils verschobenen Lage eines neuen Nidationsfeldes auf eine Abgrenzung des Endometriums in sogenannte „Implantationsfelder" geschlossen und daraus weitgehende Konsequenzen im Hinblick auf die Menstruation und ihre Bedeutung für die Implantation geźogen (STrauss 1944a und $b$ ).

Aus einer Arbeit von van der Horst and Gillman (1941) entnehmen wir die für unser Problem bedeutende Angabe, dass bei Elephantulus das Menstruationsfeld mit dem Implantationsfeld zusammenfällt, wobei es in diesem zu einer hochgradigen Erweiterung der Drüsen und zu den bekannten Gefässveränderungen 
kommt. Wir erblicken darin ein Analogon zu unseren Feststellungen bei Ericulus und Hemicentetes. Mit anderen Worten: die endometriale Reaktion, die wir als keimbedingt ansehen, umfasst wenn wir vorerst die Drüsenveränderungen und die Veränderungen am Gefässapparat im Auge behalten wollen - einen ganz eng umschriebenen Bereich der Schleimhaut. Dieser scheint mit dem zukünftigen Implantationsfeld identisch zu sein und fängt an, morphologisch sich zu differenzieren, noch ehe es zu einem engen Kontakt zwischen Keim und mütterlicher Schleimhaut gekommen ist.

Am Oberflächenepithel gestalten sich die spezifischen keimbedingten Differenzierungen in verschiedenen Graden der Ausbildung. Für unsere Objekte konnten wir lediglich eine leichte Mulden- und Grubenbildung im Epithel (Hemicentetes, Ericulus) beschreiben, die offenbar nur einen verschieden entwickelten Zustand ein und desselben Vorganges darstellen.

Bei Ericulus münden ausserdem noch Drüsen in die Epithelgrube ein und es kommt zu einer Art Becherbildung der Schleimhaut.

Bei Myotis bildet das Epithel eine Art Tasche (,,pocket"), die sehr an die bei Elephantulus beschriebene Eikammer erinnert.

Bei Elephantulus sind dann auch die Epithelveränderungen am ausgeprägtesten, indem es, nach einer deutlichen weiteren Höhenzunahme, noch eher der Trophoblast gewuchert ist, zu einer Degeneration der Zellen kommt.

Für den Menschen und den Rhesus-Affen liegen die Epithelveränderungen ausserhalb unserer Betrachtungen, weil sie in einem Zeitpunkt erfolgen, wo die Trophoblastschale zu wuchern beginnt und eine direkte Zellalteration durch den Trophoblast nicht mehr ausgeschlossen werden kann.

Des weiteren sind nun die übrigen Veränderungen an der Schleimhaut beim Menschen und beim Rhesus-Affen zu verfolgen. Hertig and Rock (1945) beschriehen in einer jüngsten Arbeit zwei menschliche frühimplantierte Keime in einem Alter von 7 und 9 Tagen. In beiden Fällen entspricht das Endometrium dem 22. bezw. 25. Tag eines 28 tägigen Cyklus und zeigt alle morphologischen Merkmale der praegraviden Schleimhaut (Abb. 45). Im Lumen der Drüsen befindet sich glykogenhaltiger Schleim, das Stroma ist mässig oedematös und entbehrt der Mitosen. Im Endo- 
metrium mit dem älteren Keim ist die praedeziduale Umwandlung der Bindegewebszellen unter dem Epithel weiter fortgeschritten als es bei der Schleimhaut mit dem jüngeren Ei der Fall ist.

Vergleichen wir nun diese Verhältnisse mit jenen in der unmittelbaren Nachbarschaft der Keime, so fällt sofort die Tatsache in die Augen, dass irgenwelche besondere morphologische Differenzierungen fehlen. Das Endometrium ist in seiner Struktur in keiner Weise anders gebaut als in den keimfreien Abschnitten. Es kann also von einer keimbedingten Reaktion von seiten der Schleimhaut gar nicht die Rede sein. Wir wollen aber gleich festhalten, dass sie nicht ausbleibt, aber in einem Zeitpunkt erfolgt, der mit praeimplantativem Zustand nichts mehr zu tun hat.

Für den Rhesus-Affen sind noch frühere Stadien (Keimanlagerung) beschrieben worden (Wislocki and StreEter 1938), aber auch sie zeigen keine Schleimhautreaktion (Abb. 44). Das Endometrium ist in allen seinen Abschnitten - ob Keimbezirk oder nicht - gleich gebaut und entspricht der praegraviden Phase. Post implantationem finden wir aber sofort alle Zeichen einer Gewebsreaktion und diese nicht nur auf der Keimseite, sondern auch auf der gegenüberliegenden Schleimhaut. Doch liegen diese morphologischen Umgestaltungen ausserhalb unserer Betrachtung.

Wie ist nun diese Diskrepanz im Verhalten des Endomestriums bei den verschiedenen Säugetieren und beim Menschen zu erklären? Warum finden wir bei den einen Vertretern (Ericulus, Hemicentetes, Elephantulus und Myotis) eine ausgesprochene endometriale Reaktion auf die Anwesenheit des Keimes, und warum nicht beim Rhesus-Affen und beim Menschen?

Wir müssen bei der Formulierung unserer Antwort darauf hinweisen, dass die endometriale Reaktion in beiden Fällen eintritt -nur erscheint sie bei jenen erstgenannten Individuen früher, d. h. praeimplantativ und in der zweitgenannten Gruppe später, nämlich nach der Implantation (genauer: während der Epithelpassage oder gar nach ihr) und ist dann für uns als Reaktion weitaus verständlicher und wohl auch selbstverständlicher, weil das Ei schon in die Schleimhaut eingedrungen ist.

Die Dinge stehen nun offenbar in einem engen Zusammenhang mit dem Entwicklungsstadium der Keime und es scheint der Zeitfaktor mit ein Grund dafür zu sein, ob und wann praeimplantative Gewebsdifferenzierungen auftreten. Bei Hemicentetes, Myotis und 
Elephantulus gelangt das Ei als Blastula, bzw. als Mehrzellenstadium, bzw. als Vierzellenstadium ins Cavum uteri, bei Ericulus wohl als Blastocyste, aber $\mathrm{mit}$ e rhalten e $\mathrm{Z}$ on a pel$1 \mathrm{u}$ c i d a. In allen Fällen aber erfolgt die Implantation im Stadium der freien Blastocyste und es verstreicht mithin zwischen der Ankunft des Keimes und seiner Einbettung eine Spanne Zeit, während welcher das Endometrium sich in seinem morphologischen Gefüge metamorphosieren kann. In dem Fall aber, wo bereits eine reife Blastocyste in den Uterus eintritt, wie das beim Rhesus-Affen und wohl auch beim Menschen die Norm ist, bleibt für eine praeimplantative Reaktion keine Zeit übrig; und es kann daher eine Reaktion auch nicht manifest werden, solange der Keim noch ausserhalb der Schleimhaut (aber ihr angelagert) sich befindet. Ein weiterer Grund liegt wohl auch in der Tatsache, dass die Implantation rasch erfolgen muss, wie aus der neuesten Arbeit von Hertig and Rock hervorgeht. Wenn dann die Umstellungen an Drüsen und Stroma erfolgen, hat die Implantation bereits stattgefunden und ihre Folgen sind für unser kausales Denken fassbarer geworden. (Wir verweisen an dieser Stelle auf die tabellarische Zusammenfassung am Ende des Textes.)

Ähnliche Gedankengänge wie wir sie oben dargelegt haben, haben auch schon van DER Horst and Gillman (1942 $b$ ) geäussert und auch Strauss (1944a) versuchte die eben geschilderten Vorgänge ähnlich zu deuten. Die beiden südafrikanischen Forscher geben der Meinung Ausdruck, die praegravide Schleimhaut bilde sich beim Tod der Eier oder wenn eine Befruchtung ausgeblieben ist, während die frühgravide (praeimplantative) Mucosa faktisch durch die Gegenwart des Keimes bedingt ist. Das bedeutet, dass vom lebenden Ei Einflüsse (welcher Art?) auf die Schleimhaut bestehen, die diese zur Metaporphose anregen. Mit anderen Worten: das Ei verhält sich nicht als ein Fremdkörper, sondern als ein Wesen eigener Art, das dem Endometrium gegenüber seine lebendigen Potenzen geltend macht.

Nach all diesen Befunden und Erkenntnissen stellen sich uns die Verhältnisse so dar, dass wir begrifflich zwei Dinge, die in Tat und Wahrheit ein g an zes Phaenomen a us a chen, zu unterscheiden haben. Es sind das die die Luteinphase begleitenden Veränderungen am Endometrium, die die Schleimhaut als Ganzes erfassen und der morphologische Ausdruck der hormo- 
nalen Umstellung sind. Sie sind demjenigen Zustand gleichzustellen, den man beim Menschen als praemenstruelle Schleimhaut bezeichnet hat. Da wir in ihnen die Vorbereitung auf eine zukünftige Eiaufnahme sehen, werden sie als p r a e g r a vi d e S c h l e i m ha $\mathrm{utph}$ a se benannt. Ist eine Befruchtung eingetreten und kommt es damit zu einer Implantation, dann treten an der Schleimhaut lo k a le Anpassungserscheinungen auf, für die wir die Anwesenheit des Keimes verantwortlich machen. Sie erfolgen, noch ehe eine innige Kontaktnahme zwischen Ei und Schleimhaut zustande gekommen ist, bei allen jenen Säugetieren, bei denen zwischen dem Eintritt des Eies in den Uterus und der Implantation eine Spanne Zeit verstreicht, während welcher sich die Umgestaltungen manifestieren können. Sie sind als die eigentlichen p ra eim plantativen Veränderungen des Endometriums anzusehen. Zeitlich gehen sie den eigentlichen, tiefgreifenden Graviditätsmerkmalen voraus; sie sind aber etwas von den Veränderungen der praegraviden Schleimhautveränderungen in ihrem morphologischen Charakter, wie auch in ihrem Wesen verschiedenes.

Standen bis jetzt die praeimplantativen Anpassungsvorgänge der Schleimhaut im Blickfeld unserer Betrachtungen, so mögen im Folgenden kurz die Verhältnisse der praegraviden Schleimhaut um der Vollständigkeit willen beleuchtet werden. Die hier näher zu erörternden Veränderungen stellen sich, soweit wir es beurteilen können, allmählich während der Tubenpassage der Eier ein. Sie sind für Ericulus und Hemicentetes eingehend beschrieben worden, gelten aber auch für alle andern Säugetiere und wurden auch beim Menschen während der Tubenpassage beobachtet (AlLEN, Pratt, Newell and Bland 1930). Die Charakteristika dieser Phase erfassen die Schleimhaut als Ganzes und bilden sich unter dem Einfluss des Gelbkörperhormons aus. Dabei werden nicht nur die E p ithelkom p o n e n t e n des Endometriums von der Vorbereitungsphase erfasst, sondern im gleichen Masse erfahren das B in d e g e w e b e des Stromas und das M y o metri u m eine weitgehende Auflockerung und stärkere Durchfeuchtung. Der prägnanteste Ausdruck dafür sind die oedematöse Durchtränkung des Stromas und die auffällige Zunahme der Mitosenzahl im Stroma wie auch im Muskelbindegewebe (Streve 1926). Die sekre t o ris che Leistung der Drüsenepithelien konnte auch an unserem Material durch die Vakuolenbildung und durch das Vor- 
handensëin des Sekretes in Drüsen- und Uteruslumen belegt werden. Begreiflicherweise sind wir nicht imstande eine Aussage darüber zu machen, welcher Art der Inhalt dieser Vakuolen sei. Für viele Tiere und besonders für den Menschen wurde eine $\mathrm{Z} \mathrm{un}$ a h m e d e s G ly k o ge n s und der Li p o i d e in den Drüsenzellen und im Stroma festgestellt (Aschнeim 1915, Driessen 1911, Schröder 1930, Wegelin 1911 und Rossman 1941, cit n. Strauss 1944a).

Parallel mit den Drüsen- und Stromaveränderungen gehen praegravide Gefässumstellungen einher, die zum Teil auch verantwortlich gemacht werden für das Stromaoedem und die leukocytäre Infiltration der praegraviden Mucosa beim Menschen (MARkEE cit. n. Strauss 1944a). Auch sie sollen der Steuerung durch ovarielle Einflüsse unterliegen.

\section{Epoophoron und Vagina.}

Schon Kreutzer (1937) hat die Vermutung geäussert, dass die Bildung des Epoophoron keine rudimentäre sein könne und diese Ansicht durch die Tatsache gestützt, dass das Epoophoron nach der Geburt an Grösse zunimmt und dass ferner die Weite der Kanälchen und ihre Windungen in den verschiedenen Alterssufen nicht gleich sind. Leider stand die ausführliche Arbeit Wiснмanns (cit. n. LANDAU) über die Verhältnisse bei der Frau nicht zur Einsichtnahme zur Verfügung, sodass wir uns hier einer vergleichenden Kritik enthalten müssen. Hingegen hat LANDAU die Meinung Kreutzers geteilt und wir glauben auch nach unseren Befunden, dass in morphologischer Hinsicht wenigstens das Epoophoron an den cyklischen Veränderungen ebenso beteiligt ist; wie die übrigen Genitalabschnitte. Eine Frage aber muss wohl unbeantwortet bleiben, nämlich die nach dem Charakter des Sekretes und nach seiner physiologischen Bedeutung. Morphologisch bestehen enge Beziehungen des Epoophoron mit dem Periovarialraum, indem sich die Epoophoronkanälchen via rete ovarii in diesen öffnen.

Am Ende unserer Betrachtungen möchten wir noch einmal darauf hinweisen, dass die unter der Wirkung des Gelbkörperhormons stehenden Organe des Genitaltraktes alle ohne Ausnahme dieselben morphologischen und funktionellen Erscheinungen zeigen, nämlich eine Vermehrung ihrer sekretorischen Leistung, eine bessere Durchblutung und Auflockerung ihrer Gewebe. Dies€ Auf- 
lockerung erstreckt sich auch auf die $\mathrm{V}$ a g i n a und betrifft dort in gleicher Weise das Bindegewebe wie das Epithel (Quellung). Eine Sinndeutung der vaginalen Epitheldesquamation zu geben, würde - wenn wir sie in finaler Hinsicht versuchen wollten - wohl ebenso dürftig ausfallen, wie beim Epoophoron. Wenn wir aber von jeder Finalität absehen, so möchten wir sagen, dass es sich auch da offenbar um eine biologische Reminiszenz des Müller'schen Schlauches handelt. Gerade die Einerleiheit der Erscheinungen scheint uns das Typische an den beschriebenen Vorgängen der praegraviden Phase zu sein und wir betrachten dies als einen Fingerzeig dafür, dass eine lebendige Erscheinung, sei sie nun hormonaler oder anderer Art, nie nur ein engumschriebenes, auf ein bestimmtes Organ gerichtetes, funktionelles oder morphologisches Geschehen ist.

\section{ZUSAMMENFASSUNG}

In der vorliegenden Studie ist der Versuch unternommen worden, auf die im Titel der Arbeit ${ }^{1}$ gestellte Frage Antwort zu geben. Dazu war es notwendig, die praegraviden Veränderungen von der praeimplantativen Schleimhautreaktion zu trennen.

Die praegravide Umstellung erfasst generell den ganzen Genitaltrakt und ist durch den hormonalen Einfluss des Corpus luteum bedingt. Sie stellt von seiten des Endometriums aus betrachtet den mütterlichen Beitrag zur Implantation dar.

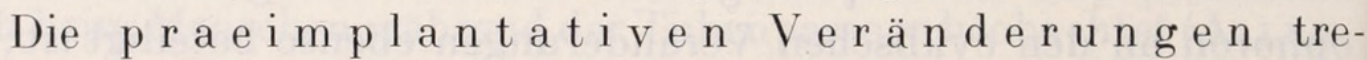
ten nur am Endometrium zutage und dort nur in dem vom Keim als Implantationsort benützten Bezirk. Sie bestehen in einer ausgeprägten $\mathrm{Proliferation}$ am Epithel, die zu einer Mulden- oder Grubenbildung führc (Ericulus, Hemicentetes), bei anderen Säugetieren Grund zu einer Taschenbildung ist.

Am D r üs e n a p a rat zeigt sich die Reaktion in Form cystischer Erweiterungen.

Das Stro m a erfährt subepithelial eine starke Verdichtung und eine ausgesprochene deziduale Umwandlung seiner Zellen.

1 Der Titel der Preisaufgabe lautete: Welche geweblichen Veränderungen im weiblichen Genitalapparat der Säugetiere kennzeichnen die sogenannte Praeimplantationsphase der Schwangeschaft? 


\begin{tabular}{|c|c|c|c|c|c|c|}
\hline 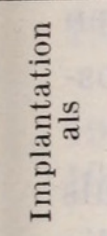 & $\begin{array}{l}0 \\
0 \\
0 \\
0 \\
0 \\
0 \\
\frac{0}{02} \\
\frac{\pi}{n}\end{array}$ & 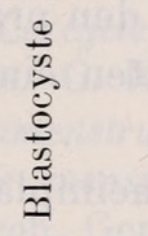 & 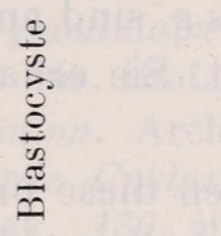 & $\begin{array}{l}\frac{0}{n} \\
0 \\
0 \\
0 \\
\frac{0}{02} \\
\frac{\pi}{n}\end{array}$ & $\begin{array}{l}\frac{0}{n} \\
3 \\
0 \\
0 \\
\frac{0}{02} \\
\frac{\pi}{n}\end{array}$ & $\begin{array}{l}\frac{0}{0} \\
\frac{0}{u} \\
0 \\
\frac{0}{0} \\
\frac{\pi}{x}\end{array}$ \\
\hline 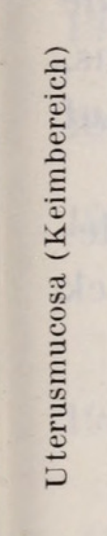 & 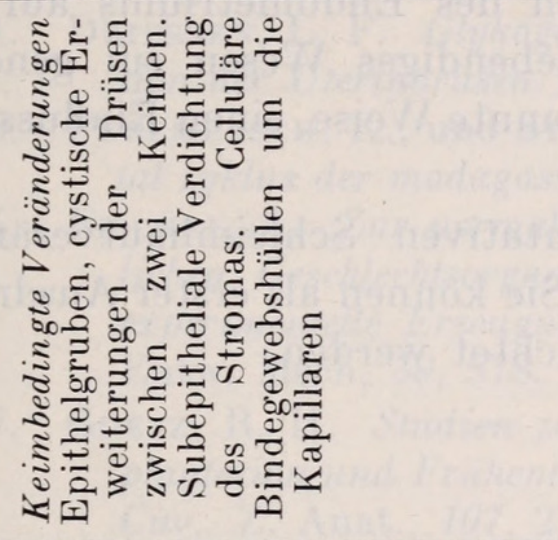 & 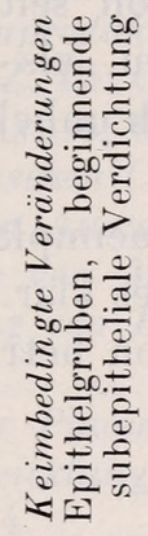 & 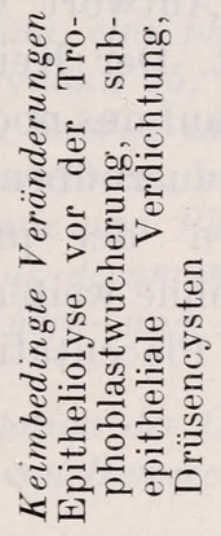 & 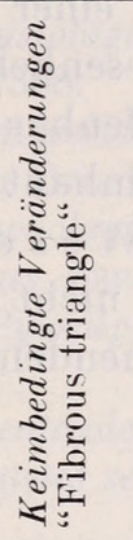 & 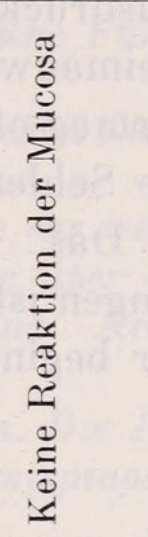 & 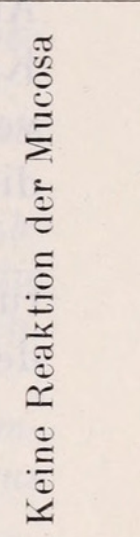 \\
\hline 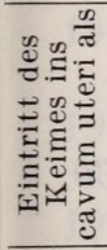 & 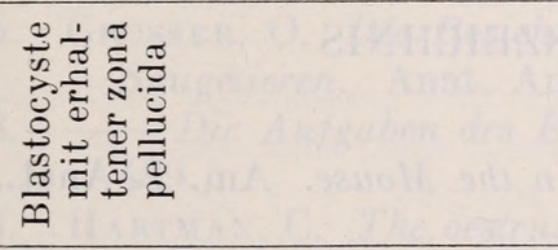 & $\frac{\frac{\pi}{J}}{\frac{\pi}{02}}$ & 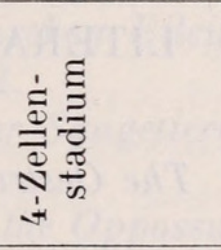 & 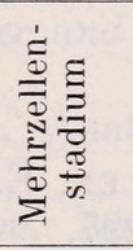 & 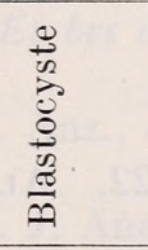 & $\begin{array}{l}\frac{9}{0} \\
\frac{0}{0} \\
0 \\
\frac{0}{0} \\
\frac{\pi}{x}\end{array}$ \\
\hline 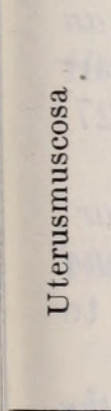 & 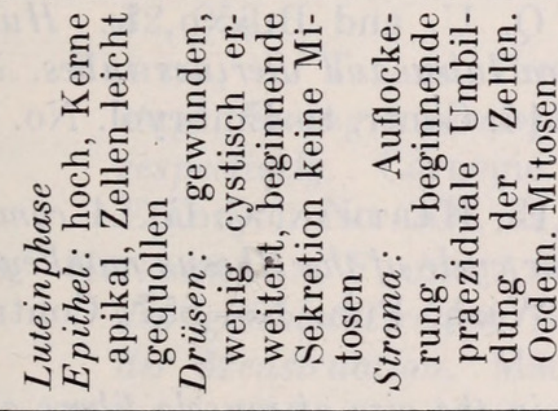 & 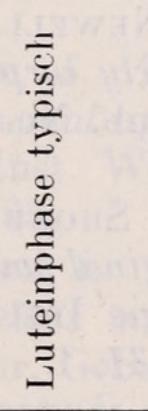 & 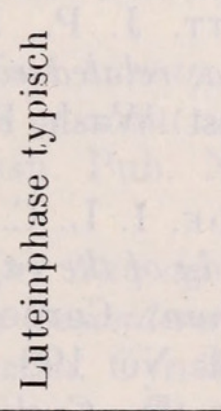 & 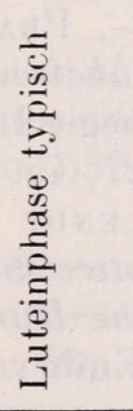 & 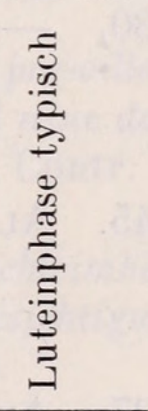 & 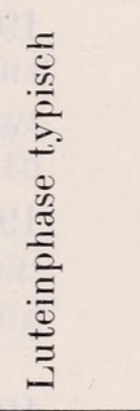 \\
\hline 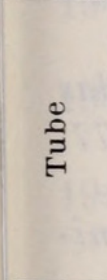 & 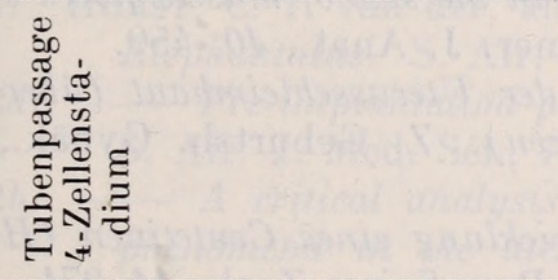 & 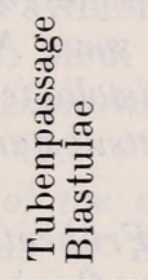 & & 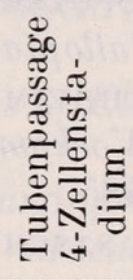 & 1 & 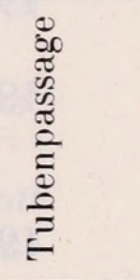 \\
\hline $\begin{array}{l}\text { कै } \\
0 \\
0\end{array}$ & $\begin{array}{l}\dot{\Xi} \\
\dot{0} \\
\dot{0}\end{array}$ & $\begin{array}{l}\dot{\Xi} \\
\dot{\Xi} \\
\dot{0}\end{array}$ & $\begin{array}{l}\dot{\Xi} \\
\dot{\Xi} \\
\dot{0}\end{array}$ & $\begin{array}{l}\dot{\Xi} \\
\dot{\Xi} \\
\dot{\Xi}\end{array}$ & $\begin{array}{l}\dot{\Xi} \\
\dot{\Xi} \\
\dot{0}\end{array}$ & $\begin{array}{l}\dot{\Xi} \\
\dot{\Xi} \\
\dot{0}\end{array}$ \\
\hline$\frac{\frac{\overrightarrow{4}}{2}}{\frac{0}{0}}$ & 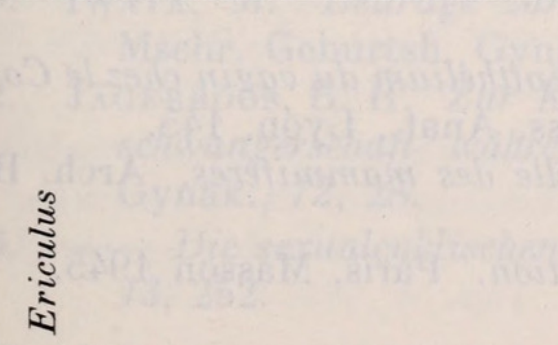 & 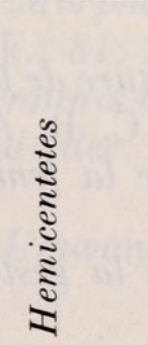 & 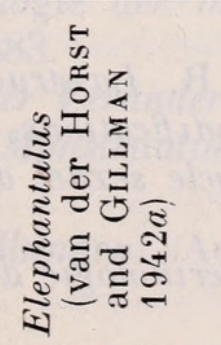 & 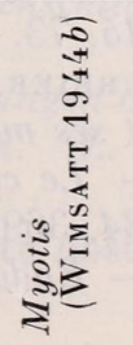 & 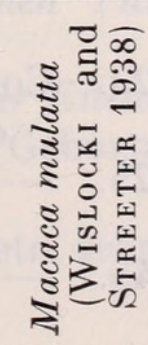 & 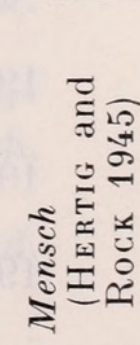 \\
\hline
\end{tabular}

Rev. Suisse de Zool., T. 55, 1948. 
Die G e f äs s e sind an den praeimplantativen Veränderungen ebenfalls beteiligt. Sie erhalten eine breite zelluläre Bindegewebshülle.

Wir betrachten diese praeimplantativen Differenzierungen als Ausdruck einer Antwort von seiten des Endometriums auf die Keimanwesenheit. Der Keim, als lebendiges Wesen sui generis, vermag offenbar auf uns noch unbekannte Weise, einen Einfluss auf die Schleimhaut auszuüben.

Das $W$ es e $n$ der praeimplantativen Schleimhautveränderungen ist nicht ohne weiteres klar. Sie können als erster Ausdruck der beginnenden Placentation betrachtet werden.

\section{LITERATURVERZEICHNIS}

1922. Allen, E. The Oestrus Cycle in the Mouse. Am. J. Anat., 30, 297.

1930. - Pratt, J. P., Newell, Q. U. and Bland, L. Human tubal ova, related early corpora lutea and uterines tubes. Carnegie Inst. Wash. Pub. No. 414, Contr. to Embryol. No. 127, $2 \%, 45$.

1945. Allende de, I. L. C., Shorr, E., Hartman, C. G. A comparative study of the vaginal smear cycle of the Rhesus monkey and the Human. Carnegie Inst. Wash. Pub. No. 557, Contr. to Embryol. No. 198, 31, 1.

1927. Anopolsky, D. Cyclic changes in the size of muscle fibers of the fallopian tube of the sow. Amer. J. Anat., 40, 459.

1915. Аsсннегм, S. Zur Histologie der Uterusschleimhaut (über das Vorkommen von Fettsubstanzen). Z. Geburtsh. Gynäk., F\%, 485.

1937. Bluntschli, H. Die Frähentwicklung eines Centetinen (Hemicentetes semi-spinosus Cuv). Rev. Suisse Zool., 44, 271.

1927. Вuтомо, W. Zur Frage von den cycklischen Veränderungen in den Tuben (über Tubenlipoide). Arch. Gynäk., 131, 307.

1923. Corner, G. W. Ovulation and Menstruation in Macacus Rhesus. Carnegie Inst. Wash. Pub. No. 75, Contr. to Embryol. No. 75, $15,73$.

1923. Courrier, R. La structure de l'épithélium du vagin chez le Cobaye et ses modifications. C. R. Ass. Anat., Lyon, 145.

1925. L Le cycle sexuel de la femelle des mammifères. Arch. Biol., 34, 369 .

1945. Endocrinologie de la gestation. Paris, Masson 1945. 
1922. - et Gerlinger, H. Le cycle glandulaire de l'épithélium de l'oviducte chez la chienne. C. R. Soc. Biol., 2, 1363.

1908. Czyzewicz, A. Zur Tubenmenstruation. Arch. Gynäk., 85, 197.

1927. Diевкs, K. Der normale mensuelle Cyklus der menschlichen Vaginalschleimhaut. Arch. Genäk., 130, 46.

1911. Driessen, L. F. Glykogenproduktion, eine physiologische Funktion der Uterindrüsen. Z. Bl. Gynäk., 35, 1308.

1949. Feremutsch, K., und Strauss, F. Beitrag zum weiblichen Genital zyklus der madagassischen Centetinen. Im Druck.

1914. Fischel, A. Zur normalen Anatomie und Physiologie der weiblichen Geschlechtsorgane von Mus decumanus sowie über die experimentelle Erzeugung von Hydro- und Pyosalpinx. Arch. Entw. Mech, 39, 578.

1937. Goetz, R. H. Studien zur Placentation der Centetiden. Die Implantation und Frühentwicklung von Hemicentetes semispinosus Cuv. Z. Anat., 10\%, 274.

1915. Grosser, O. Die Beziehungen zwischen Eileiter und Ei bei den Säugetieren. Anat. Anz., 48, 92.

1918. — Die Aufgaben des Eileiters der Säugetiere. Anat. Anz., 50, 489.

1923. Hartman, C. The oestrus cycle in the Oppossum. Am. J. Anat., $32,353$.

1945. Hertig, A. T. and Rock, J. Two human ova of pre-villous stage, having a developmental age of about seven and nine days respectively. Carnegie Inst. Wash. Pub. No. 557, Contr. to Embryol. No. 200, 31, 65.

1908. Hitschmann, F. und Adler, L. Der Bau der Uterusschleimhaut des geschlechtsreifen Weibes mit besonderer Berücksichtigung der Menstruation. Mschr. Geburtsh. Gynäk., 2\%, 1.

1941. Horst, C. I. van der, and Gillman, I. The menstrual cycle in Elephantulus. S. Afr. J. Med. Sci., 6, 27.

1942a. Pre-implantation phenomena in the uterus of Elephantulus. S. Afr. J. Med. Sci., 7, 47.

1942b. A critical analysis of the early gravid and pre-menstrual phenomena in the uterus of Elephantulus, Macaca and the Human female. S. Afr. J. Med. Sci., 7, 134.

1946. - The reactions of the uterine blood vessels before, during and after pregnancy in Elephantulus. S. Afr. J. Med. Sci., 11, Biol. Suppl., 103.

1929. Imata, M. Beiträge zur Morphologie der menschlichen Tube. Mschr. Geburtsh. Gynäk., 81, 283.

1912. JäGERroos, B. H. Zur Kenntnis der Veränderungen der Eileiterschwangerschaft während der Menstruation. Z. Geburtsh. Gynäk., 72, 28.

1933. - Die sexualcyklischen Umwandlungen. Acta obstetr. scand. 13, 252 . 
1939a. Joel, K. The Glycogen Content of the Fallopian Tubes during the Menstrual Cycle and during the Pregnancy. J. Obstet. Gynaec. Brit. Emp., 46, 721.

1939b. - The Lipoid Content of the Fallopian Tubes during the Menstrual Cycle and during Pregnancy. J. Obstet. Gynaec. Brit. Emp., 46, 731.

1940. _ Zur Histologie und Histochemie der menschlichen Eileiter während Cyclus und Schwangerschaft. Mschr. Geburtsh. Gynäk., 110, 252.

1909. Keller, K. Über den Bau des Endometriums beim Hunde. Anat. H., 39, 309.

1946. Kos, L. Contribution à l'étude de la néoformation d'ovules chez les mammifères primitifs adultes. Rev. Suisse Zool., T. 53, p. 597.

1937. Kreutzer, H. Über die Reste der weiblichen Urogenitalverbindung (Epoophorn und Rete ovarii) bei einigen Säugetieren. Arch. Néerl. Zool., 3, 1.

1892. LANdAU und Rheinstein. Über das Verhalten der Schleimhäute in verschlossenen und missbildeten Genitalien und über Tubenmenstruation. Arch. Gynäk., 42, 273.

1938. Landau, R. Der ovariale und tubale Abschnitt des Genitaltraktus beim nicht-graviden und beim frühgraviden Hemicentetesweibchen. Bio-Morph., 1, 228.

1877. Leopold, G. Studien über Uterusschleimhaut während Menstruation, Schwangerschaft und Wochenbett. Arch. Gynäk., 11, 110.

1922. Long, J. A. and Evaxs, H. M. The oestrus cycle in the rat. Mem. of Univ. California, 6, 1 .

1899. Mannzer, F. Zur Etiologie und Therapie der Gynatresien, insbesondere der Haematosalpinx bei Gynatresie. Arch. Gynäk., $5 \%, 681$.

1940. MarкеE, J. E. Menstruation in intraocular endometrial trans plants in the Rhesus monkey. Carnegie Inst. Wash. Pub. No. 518, Contrib. to Embryol. No. 177, 28, 221.

1934. Minalik, von, P. Über die Bildung des Flimmerapparates im Eileiterepithel. Anat. Anz., 79, 259.

1913. Moreau, R. Recherches sur la morphologie et la fonction glandulaire de l'épithélium de la trompe utérine chez les mammifères. Arch. Anat. Micr., 14, 515.

1928. Moser, E. M. Untersuchungen über zyklische Veränderungen der zytologischen Bestandteile des Vaginalsekretes beim Menschen. Diss. med. Zürich.

1928. Nahano, O. Über die Verteilung des Glykogens bei den cycklischen Veränderungen in den Geschlechtsorganen der Fledermaus und über die Nahrungsaufnahme der Spermien in den weiblichen Geschlechtswegen. Fol. Anat. Jap., 6, 777. 
1928. Novak, E. and Everett, H. S. Cyclical and other variations in the tubal epithelium. Am J. Ostetr., 16, 499.

1948. Papanicolaou, G.N., Traut, H.F., and Marchetti A.A. The epithelia of woman's reproductive organs. New York: The Commenwealth Fund.

1941. Rossman, I. Cyclic changes in the endometrial lipins of the Rhesus monkey. Am J. Anat., 69, 187.

1908. Schaffer, J. Über Bau und Funktion des Eileiterepithels beim Menschen und bei Säugetieren. Mschr. Geburtsh. Gynäk., $28,526$.

1940. Schaffner, A. Untersuchungen über die Morphologie und den Glykogengehalt der menschlichen Eileiter. Diss. med. Basel.

1926. Sснеуев, E. Über die Lipoide der Tube. Virch. Arch., 262, 712.

1914. SсноӧDев, R. Über das Verhalten der Uterusschleimhaut um die Zeit der Menstruation. Mschr. Geburtsh. Gynäk., 39, 3.

1915. _ Anatomische Studien zur normalen und pathologischen Physiologie des Menstruationszyklus. Arch. Gynäk., 104, 27.

1930. _W _Weibliche Genitalorgane" in: Mollendorff, von Handb. Mikr. Anat. Mensch. Berlin, Springer, Bd., $\%$.

1923. SNyder, F. F. Changes in the Fallopian tube during the ovulation and early pregnancy. Bull. Johns Hopkins Hosp., 34, 121.

1924. - Changes in the human oviduct during menstrual cycle and pregnancy. Bull. Johns Hopkins Hosp., 35, 141.

1914. Sовотта, J. Zur Frage der Wanderung des Säugetiereies durch den Eileiter. Anat. Anz., 4\%, 448.

1916. _ _ Über den Mechanismus der Aufnahme der Eier der Säugetiere in den Eileiter und des. Transportes durch diesen in den Uterus. Anat. H., 54, 361.

1925. Stieve, H. Das Schwangerschaftswachstum und die Geburtserweiterung der menschlichen Scheide. Z. mikr.-anat. F., 3, 307.

1926. Die regelmässigen Veränderungen der Muskulatur und des Bindegewebes in der menschlichen Gebärmutter in ihrer Abhängigkeit eines gelben Körpers, nebst Beschreibung eines menschlichen Eies im Zustand der ersten Reifeteilung. Z. mikr.anat. F., 6, 351.

1917. Stockard, S. and Papanicolaou, G. The existence of a typical oestrous cycle in the guinea-pig with a study of its histological and physiological changes. Am. J. Anat., 22 (war nicht zugänglich).

1938. Strauss, F. Die Befruchtung und der Vorgang der Ovulation bei Ericulus aus der Familie der Centetiden. Bio-Morph., 1, 282,

1939. _ Die Bildung des Corpus luteum bei Centetiden. Bio-Morph.. 1, 489 .

1943. - Die Placentation von Ericulus setosus. Rev. Suisse Zool., 50, 17. 
1944a. Die Implantation des Keimes, die Frühphase der Placentation und die Menstruation. Bern, Haupt.

1944b. - Die Abhängigkeit der Implantation von der Anordnung und dem Funktionszustand der Uterusgefässe. Mschr. Geburtsh. Gynäk., 118, 249.

1946. Le coussin de la bourse ovarienne chez un Centétidé. Bull. Histol. appl., 23, 153.

1929. Tietze, K. Zur Frage nach den cycklischen Veränderungen des menschlichen Tubenepithels. Zbl. Gynäk., 53, 32.

1931. Klinisch-anatomische Studien am Ovarialtumormaterial der Kieler Frauenklinik. Arch. Gynäk., 146, 197.

1917. Tröscher, H. Über Bau und Funktion des Tubenepithels beim Menschen. Mschr. Geburtsh. Gynäk., 45, 205.

1929. Walter, L. Zur Kenntnis der flimmerlosen Epithelzellen der menschlichen Tubenschleimhaut. Anat. Anz., 67, 138.

1911. Wegelin, C. Der Glykogengehalt der menschlichen Uterusschleimhaut. Zbl. Path., 22, 1.

1916. Westman, A. Sezernierende Zellen im Epithel der Tuba uterina Fallopii. Anat. Anz. ,49, 335.

1916. Wichunn, S. E. Das Epoophoron, seine Anatomie und Entwicklung beim Menschen von der Embryonalzeit bis ins Greisenalter. Helsinfors (war mir nicht zugänglich).

1944a. Wimsatt, W. A. Growth of the ovarian follicle and ovulation in Myotis lucifugus lucifugus. Am. J. Anat., 74, 129.

1944b. An analysis of implantation in the bat, Myotis lucifugus lucifugus. Am. J. Anat., 74, 355.

1938. Wislocki, G. B. and Streeter, G. L. On the placentation of the Macaque (Macaca mulatta) from the time of implantation until the formation of the definitive placenta. Carnegie Inst. Wash. Pub. No. 496, Contr. to Embryol. No. 160, 2\%, 1. 


\section{$2 \mathrm{BHL}$ Biodiversity Heritage Library}

Feremutsch, Kurt. 1948. "Der praegravide Genitaltrakt und die Praeimplantation." Revue suisse de zoologie 55, 567-620. https://doi.org/10.5962/bhl.part.117897.

View This Item Online: https://www.biodiversitylibrary.org/item/148889 DOI: https://doi.org/10.5962/bhl.part.117897

Permalink: https://www.biodiversitylibrary.org/partpdf/117897

\section{Holding Institution}

American Museum of Natural History Library

\section{Sponsored by}

BHL-SIL-FEDLINK

\section{Copyright \& Reuse}

Copyright Status: In copyright. Digitized with the permission of the rights holder.

Rights Holder: Muséum d'histoire naturelle - Ville de Genève

This document was created from content at the Biodiversity Heritage Library, the world's largest open access digital library for biodiversity literature and archives. Visit BHL at https://www.biodiversitylibrary.org. 